\title{
The mTOR/ULK1 signaling pathway mediates the autophagy-promoting and osteogenic effects of dicalcium silicate nanoparticles
}

\author{
Wang Ruolan ${ }^{1,2}$, Chen Liangjiao ${ }^{3}$ and Shao Longquan ${ }^{1,2^{*}}$ (1)
}

\begin{abstract}
A novel bioactive inorganic material containing silicon, calcium and oxygen, calcium silicate $\left(\mathrm{Ca}_{2} \mathrm{SiO}_{4}, \mathrm{C}_{2} \mathrm{~S}\right)$ with a CaO$\mathrm{SiO}_{2}$ ingredient, has been identified as a potential candidate for artificial bone. Autophagy has an essential function in adult tissue homoeostasis and tumorigenesis. However, little is known about whether silicate nanoparticles $\left(C_{2} S\right.$ NPs) promote osteoblastic differentiation by inducing autophagy. Here we investigated the effects of $\mathrm{C}_{2} \mathrm{~S} N \mathrm{~N}$ s on bone marrow mesenchymal stem cell differentiation (BMSCs) in osteoblasts. Furthermore, we identified the osteogenic gene and protein expression in BMSCs treated with $\mathrm{C}_{2} \mathrm{~S} N \mathrm{NP}$. We found that autophagy is important for the ability of $\mathrm{C}_{2} \mathrm{~S} N \mathrm{~N}$ s to induce osteoblastic differentiation of BMSCs. Our results showed that treatment with $\mathrm{C}_{2} \mathrm{~S} N P s$ upregulated the expression of BMP2, UNX2, and OSX in BMSCs, and significantly promoted the expression of LC3 and Beclin, while P62 (an autophagy substrate) was downregulated. $C_{2} S$ NP treatment could also enhance Alizarin red $S$ dye (ARS), although alkaline phosphatase (ALP) activity was not significantly changed. However, all these effects could be partially reversed by 3-MA. We then detected potential signaling pathways involved in this biological effect and found that $\mathrm{C}_{2} \mathrm{~S} N \mathrm{~N}$ s could activate autophagy by suppressing mTOR and facilitating ULK1 expression. Autophagy further activated $\beta$-catenin expression and promoted osteogenic differentiation. In conclusion, $\mathrm{C}_{2} \mathrm{~S} N \mathrm{~N}$ s promote bone formation and osteogenic differentiation in BMSCs by activating autophagy. They achieve this effect by activating mTOR/ ULK1, inducing autophagy, and subsequently triggering the WNT/ $\beta$-catenin pathway to boost the differentiation and biomineralization of osteoblasts.
\end{abstract}

Keywords: Dicalcium silicate, Osteogenesis, Autophagy, MTOR/ULK1

\section{Introduction}

Injuries, trauma, tumors, and other bone diseases are the major causes of bone defects and thus pose immense challenges for orthopedic and reconstructive surgeons. In addition, with the increase in the aging population, age-related bone loss is an urgent problem to be solved. The development of bone substitute materials provides good perspective towards bone defect management

*Correspondence: shaolongquan@smu.edu.cn

${ }^{1}$ Nanfang Hospital, Southern Medical University, Guangzhou 510515, China

Full list of author information is available at the end of the article
[1]. In recent years, it has been found that silicon-containing bioactive materials stimulate cell proliferation, activate the expression of osteogenic genes, and demonstrate a favorable capacity for osteogenesis both in vitro and in vivo [2]. As an important ingredient of Portland cement, dicalcium silicate $\left(\mathrm{Ca}_{2} \mathrm{SiO}_{4}, \mathrm{C}_{2} \mathrm{~S}\right)$ is also an essential element in the calcium-silicate system, and it has good prospects for bone defect regeneration. In general, it is acknowledged that a precondition for the binding of both materials and living bone tissue is the establishment of a bone-like hydroxyapatite layer, which is an indication of biological activity [3]. Additionally, with favorable reproducibility, biocompatibility, leakproofness, 
and antimicrobial potential, dicalcium silicate has been shown to trigger the secretion of cytokines by osteoblasts, as well as to possess the ability to promote hard tissue formation [4-6]. Prior research has demonstrated the promising biological activity, biocompatibility, and mechanical performance of $\gamma-\mathrm{Ca}_{2} \mathrm{SiO}_{4}$ ceramics and their ability to support mesenchymal stem cell adhesion and spreading. Another study has demonstrated that $\mathrm{C}_{2} \mathrm{~S}$-released silicon ions are essential in bone repair [79]; thus, $\mathrm{C}_{2} \mathrm{~S}$ might be a promising bone implant material.

Although the rise of various new bone replacement materials has provided new hope for bone defect repair, the mechanism(s) underlying this process are poorly understood. In the context of normal development, autophagy, as a key intracellular degradation and recycling process, has an essential role in the maintenance of homeostasis and remodeling of cells. Autophagy allows cells to deliver cytoplasmic components to the lysosome and then degrade and recycle unwanted or abnormal organelles and impaired macromolecules [10, 11]. More recently, autophagy has been shown to contribute significantly to the preservation of the differentiation capacity of stem cells, and it can also maintain bone homeostasis and protect BMSCs from oxidative stress [12-14]. Autophagy can also positively mediate osteogenesis of stem cells and osteoblasts. Research has shown that in undifferentiated cells, autophagosomes do not fuse with lysosomes, while in differentiating mesenchymal stem cells (MSCs), autophagy is activated during early differentiation [14]. While autophagy participates in osteoclast mineralization and bone homeostasis, there are reports that autophagic vacuoles serve as carriers for releasing the mineralized substrates [15]. Inhibition of autophagy could result in a reduction of bone quality in mice, which suggests that autophagy may be a vital contributor to the preservation of bone mass and osteoclast mineralization in vitro as well as in vivo $[10,16]$. Some recent research has demonstrated that particular silica nanoparticles exhibit intrinsic probiotic activity against osteogenic and osteoclastic cells $[15,17]$. Thus, in our study we speculated that autophagy is triggered by the $\mathrm{C}_{2} \mathrm{~S}$ NPs in BMSCs, and $\mathrm{C}_{2} \mathrm{~S}$ NPs then promote BMSC osteogenesis through the activation of autophagy.

Prior work has supplied evidence supporting the contribution of AMPK activation to the regulation of the differentiation and mineralization of osteoblasts in a variety of manners, such as mTOR and ULK1. As a critical mechanism responsible for cartilage generation and osteogenesis, more recent research has largely concentrated on the mammalian rapamycin target protein (mTOR) signaling pathway $[18,19]$. Studies have also shown that AMPK may induce autophagy by directly activating ULK1 or inhibiting mTOR [15]. Activation of the
AMPK/ULK1-dependent autophagy can be correlated positively with osteogenic differentiation of MSCs [20, 21], and ULK1 overexpression or rapamycin can activate autophagy and then notably elevate the osteoblast differentiation activity and restore the bone volume [22].

In the present research, we explored the impact of $\mathrm{C}_{2} \mathrm{~S}$ nanoparticles on osteoblastogenesis, and the autophagy function of BMSCs treated with $\mathrm{C}_{2} \mathrm{~S}$ NPs and the effect on differentiation. We further explored whether activation of ULK1 downstream of the mTOR pathway could enhance osteoblast differentiation and mineralization by inducing autophagy.

\section{Materials and methods \\ Preparation and characterization of $\mathrm{C}_{2} \mathrm{~S} N \mathrm{NP}$ Preparation of $\mathrm{C}_{2} \mathrm{SNPS}$}

$\mathrm{C}_{2} \mathrm{~S}$ particles of $99 \%$ purity were synthesized by the solgel process in the laboratory of Shanghai Institute of Ceramics, Chinese Academy of Sciences.

\section{Characterization of $\mathrm{C}_{2} \mathrm{SNPS}$}

Using a scanning electron microscope (SEM; Nova Nano SEM 430, FEI, Finland) combined with energy dispersive X-ray spectroscopy (DX-4 system, EDAX, USA), the particle morphology was identified. An investigation of the crystal structure was performed with X-ray diffraction (XRD; Geigerflex, Rigaku Corporation, Japan), and the diffraction pattern was determined over a range of $2 \theta$ from $10^{\circ}-80^{\circ}$ with monochromatic $\mathrm{Cu} \mathrm{K \alpha}$ radiation. Apart from the application of tetrasodium phosphate and a surfactant, with vigorous stirring (pumping at $80 \mathrm{rpm}$ and $100 \mathrm{rpm}$ cycles), an ultrasonic bath was utilized to disperse the particles. The particle size distributions that were measurable in the 64 channels ranged from around 0.1 to $150 \mu \mathrm{m}$; the ultimate size distributions were identified using Fraunhofer calculations. An atomic force microscope (AFM) (Agilent Technologies, Inc. USA) was applied to inspect the microstructure. Furthermore, a Fourier transform infrared spectrometry (FTIR) approach (Thermo Fisher Scientific Inc. USA) was conducted to analyze the chemical composition.

\section{Cell culture}

Cyagen Bioscience provided bone marrow mesenchymal stem cells (BMSCs), which were cultured in Minimum Essential Medium Eagle $-\alpha$ modification $(\alpha-M E M$, Gibco, USA) supplemented with 10\% FBS and streptomycin (Gibco; Thermo Fisher Scientific, USA) and $100 \mu \mathrm{g} /$ $\mathrm{mL}$ penicillin, in a $5 \% \mathrm{CO}_{2}$ atmosphere at $37^{\circ} \mathrm{C}$. Incubation of the first 7 passages of BMSCs was utilized for the following experiments, wherein all the media were replaced at 2-day intervals. 
In the original $\alpha$-MEM, the cell viability, proliferation, and cytoskeleton assembly were assayed. The cellular osteogenic differentiation mediated by osteogenic medium containing $10 \% \mathrm{FBS}, 50 \mathrm{mg} / \mathrm{ml}$ ascorbic acid, $10 \mathrm{nM}$ dexamethasone, and $10 \mathrm{mM}$ b-glycerophosphate, was measured by alkaline phosphatase (ALP) activity, collagen secretion, and extracellular matrix (ECM) mineralization.

\section{ICP-MS elemental analysis}

To assess the durability of $\mathrm{C}_{2} \mathrm{~S}$ NPs in growth medium, dissolution studies of $\mathrm{C}_{2} \mathrm{~S}$ were performed in complete medium. $\mathrm{C}_{2} \mathrm{~S}$ NPs were incubated in medium for $24 \mathrm{~h}$. After incubation, a $0.22-\mu \mathrm{m}$ filtration membrane was utilized to filter the suspension, and the filtered medium was collected. Inductively coupled plasma-mass spectrometry (ICP-MS; Thermo Fisher Scientific, USA) was used to determine the calcium, silicon, and phosphorus concentrations.

\section{Cell proliferation assay Cell counting kit-8 (cck-8) assay}

In 96-well plates, BMSCs were incubated with $\mathrm{C}_{2} \mathrm{~S}$ NPs of $0,10,50$ and $100 \mu \mathrm{g} / \mathrm{mL}$ at a thickness of $6 \times 10^{3} / \mathrm{cm}^{2}$ for 6,12 , and $24 \mathrm{~h}$, at 3 days and 7 days. The cellular activity was determined using the cell counting kit-8 (CCK8). After $100 \mu \mathrm{L}$ of complete medium with $10 \mu \mathrm{L}$ of cell counting kit-8 solution (Dojindo Molecular Technologies, Japan) were pumped into each well, the cells were cultured at $37^{\circ} \mathrm{C}$ for $1 \mathrm{~h}$ [23]. To obtain optical density (OD) values, the absorbance peak at $450 \mathrm{~nm}$ was identified with a microplate meter (Molecular Device, USA).

\section{Lactate dehydrogenase (LDH) assay}

The effect of $\mathrm{C}_{2} \mathrm{~S}$ NPs on cell membrane was assessed by studying the leakage of LDH from cells. In brief, a total of $6 \times 10^{3}$ BMSCs were seeded in 96-well plates and subsequently treated with $\mathrm{C}_{2} \mathrm{~S} N P$ samples at concentrations of $0,10,50$, and $100 \mu \mathrm{g} / \mathrm{mL}$ over 6,12 , and $24 \mathrm{~h}$, at 3 days and 7 days. Medium collected from each well was centrifuged, and a microplate reader (Molecular Device, USA) was employed to measure the absorption at $490 \mathrm{~nm}$.

\section{Flow cytometry assay \\ Cell cycle analysis}

A Cell Cycle and Apoptosis Analysis Kit (Beyotime, China) was used to investigate the cell cycle. Following treatment with various concentrations of $\mathrm{C}_{2} \mathrm{~S}$ NPs for $24 \mathrm{~h}, \mathrm{BMSCs}$ were subsequently collected and rinsed three times with PBS. After fixing the BMSCs in cold $\left(4{ }^{\circ} \mathrm{C}\right) 75 \%$ ethanol overnight, they were rinsed three times with PBS and stained with sodium propyl iodide (PI) in $37{ }^{\circ} \mathrm{C}$ RNase for $30 \mathrm{~min}$. Flow cytometry
(Millipore, Billerica, MA) was employed to assess all the samples.

\section{Cell apoptosis analysis}

Annexin V-fluorescein isothiocyanate (FITC) and PI were utilized to identify apoptosis. The Annexin V-FITC Apoptosis Detection Kit (Beyotime, China) was also utilized to determine the percentages of apoptotic and necrotic cells. In short, following treatment with $\mathrm{C}_{2} \mathrm{~S} N \mathrm{NP}$ sequence dilutions $(0,10,50$, and $100 \mu \mathrm{g} / \mathrm{mL})$, BMSCs were subsequently acquired at $24 \mathrm{~h}$ and 7 days and then rinsed with PBS. Based on the recommendations of the manufacturer, samples were dyed with Annexin V-FITC and PI before assessment by flow cytometry (BD FACSAria III, USA).

\section{Confocal microscopy Cell morphology}

On glass coverslips, BMSCs were sown at a thickness of $2 \times 10^{5} / \mathrm{cm}^{2}$ in 6-well plates and incubated with $\mathrm{C}_{2} \mathrm{~S}$ NPs at $0,10,50$ and $100 \mu \mathrm{g} / \mathrm{mL}$ for $24 \mathrm{~h}$. Following PBS washes, fixation with $4 \%$ cis-paraformaldehyde, dialysis with $0.5 \%$ Triton X-100, and blockade with $1 \%$ BSA, the samples were subsequently dyed with DAPI and rhodamine phosphatidylcholine, and observed by confocal microscopy (Leica SP8, Germany).

\section{Immunofluorescence assay}

BMSCs treated with various concentrations of $\mathrm{C}_{2} \mathrm{~S}$ NPs for 3,6 , and $12 \mathrm{~h}$ were coated overnight with $4 \%$ paraformaldehyde at $4{ }^{\circ} \mathrm{C}$, permeabilized with $0.01 \%$ Triton $\mathrm{X}-100$ for $20 \mathrm{~min}$ at room temperature, and blocked with $5 \% \mathrm{BSA}$ for $30 \mathrm{~min}$ at $37{ }^{\circ} \mathrm{C}$. After incubation with specific primary antibody LC3 $(1 \mu \mathrm{g} / \mathrm{ml}$ Abcam, UK) overnight at $4{ }^{\circ} \mathrm{C}$ and treatment with fluorescent secondary antibodies (1:50; Cell Signaling Technology (USA)), all the specimens were rinsed and stored at room temperature for $1 \mathrm{~h}$. The nucleus was counterstained with DAPI (Biofroxx, Germany) for 5 min at room temperature and then washed three times with PBS. The dyed cells were examined under a confocal microscope (Leica SP8, Germany). ImageJ software (NIH) was utilized to analyze cell images, where the width, perimeter, length, and area of the cells were determined, and the roundness $\left(4 \pi^{*}\right.$ Area/ [perimeter]2) and aspect ratio (length/width) was calculated. Each sample was randomly selected under 3 fields of view analyzing 3 samples per group.

\section{Transmission electron microscopy (TEM)}

TEM was utilized to examine cell adhesion and uptake. Using a concentration of 0 and $50 \mu \mathrm{g} / \mathrm{mL} \mathrm{C}_{2} \mathrm{~S} N$ Ps for $6 \mathrm{~h}$, the BMSCs were inoculated in $10 \mathrm{~cm}^{2}$ cell culture dishes for 6 h, 1 day, 3 days, and 7 days. After immobilizing the 
cultured cells in $0.1 \mathrm{M}$ malic acid buffer with $2.5 \%$ glutaraldehyde, the cells were fixed with $1 \%$ osmium tetroxide. Following ethanol dehydration, infiltration of the cells, and final embedding in Epon resin, ultrathin sections were counterstained with lead citrate and $4 \%$ urea acetate and observed under a high-resolution HT7700 transmission electron microscope (Hitachi Scientific Instruments, Japan).

\section{Alkaline phosphatase activity}

At a density of $1 \times 10^{4} / \mathrm{cm}^{2}$, the cells were seeded in 48-well plates and treated with a range of $\mathrm{C}_{2} \mathrm{~S}$ NPs at 0 , 10,50 and $100 \mu \mathrm{g} / \mathrm{mL}$ for 3,7 , and 14 days. Osteogenesis regulated by autophagy was observed, which was induced by $\mathrm{C}_{2} \mathrm{~S}$ NPs. BMSCs were treated with $0 \mu \mathrm{g} / \mathrm{mL}$ $\mathrm{C}_{2} \mathrm{~S}$ NPs, $5 \mathrm{mM}$ 3-methyladenine (3-MA), $10 \mathrm{nM}$ rapamycin, $50 \mu \mathrm{g} / \mathrm{mL} \mathrm{C}_{2} \mathrm{~S} \mathrm{NPs}, 50 \mu \mathrm{g} / \mathrm{mL} \mathrm{C}_{2} \mathrm{~S} N P s+3-\mathrm{MA}$, and $50 \mu \mathrm{g} / \mathrm{mL} \mathrm{C}_{2} \mathrm{~S}$ NPs + rapamycin for 7and 14 days. Staining and colorimetric methods were used to determine the ALP activity of BMSCs. With regard to ALP staining, samples were rinsed three times with PBS and fixed with 4\% cis-butenal for $12 \mathrm{~min}$, followed by staining with the BCIP/NBT alkaline phosphatase staining kit (Beyotime, China). Subsequently, a stereomicroscope (Leica EZ4HD, Germany) was used to photograph the samples following a PBS rinse.

\section{Mineralization}

Within the standard culture media and at a density of $1 \times 10^{4}$ cells $/ \mathrm{cm}^{2}$, the samples were seeded in 48 -well plates and incubated and treated with $0,10,50$ and $100 \mu \mathrm{g} / \mathrm{mL} \mathrm{C}_{2} \mathrm{~S}$ NPs for 7 and 14 days. We also detected osteogenesis regulated by autophagy induced by $\mathrm{C}_{2} \mathrm{~S}$ NPs. BMSCs were treated with $0 \mu \mathrm{g} / \mathrm{mL} \mathrm{C}_{2} \mathrm{~S} \mathrm{NPs,} 5 \mathrm{mM}$ 3-MA, $10 \mathrm{nM}$ rapamycin, $50 \mu \mathrm{g} / \mathrm{mL} \mathrm{C}_{2} \mathrm{~S}$ NPs, $50 \mu \mathrm{g} / \mathrm{mL}$ $\mathrm{C}_{2} \mathrm{~S} \mathrm{NPs}+3-\mathrm{MA}$, and $50 \mu \mathrm{g} / \mathrm{mL} \mathrm{C}_{2} \mathrm{~S}$ NPs + rapamycin for 7,14 , and 21 days. By salicylin red staining, extracellular mineralization was determined. After rinsing three times with PBS, the cells were immobilized with $4 \%$ cis-butenal for $15 \mathrm{~min}$ and then incubated with $0.1 \%$ salicylin red $\mathrm{S}$ (pH 4.1 Solarbio, China) at room temperature for $3 \mathrm{~min}$. Thereafter, the specimens were washed with $\mathrm{ddH}_{2} \mathrm{O}$ and were photographed under a stereomicroscope (Leica EZ4HD, Germany).

\section{Quantitative real-time PCR assay}

Gene expression was detected by qPCR. BMSCs $\left(3 \times 10^{5}\right.$ cells) were cultured with $0,10,50$ and $100 \mu \mathrm{g} / \mathrm{mL} \mathrm{C}_{2} \mathrm{~S}$ NPs in 6-well plates for 3, 7, and 14 days. Following isolation of total RNA with TRIzol and quantification with a Nano-Drop 2000 system (Thermo Fisher Scientific, USA), cDNA was reverse transcribed from each sample in accordance with the specifications of the Prime Script
RT kit (Takara, Japan). The SYBR green inLightCycler480 Sequence Detector System (Takara, Japan, Roche, Switzerland) was utilized to perform the real-time PCR. The relative mRNA expression was calculated based on the quantification of $\Delta \Delta \mathrm{Ct}$ [24]. Genes associated with osteogenesis, which include type I collagen (COLI), runt-associated transcription factor 2 (RUNX2), osterix (OSX), and bone morphogenetic protein 2 (BMP2) were identified on days 3,7 and 14 Normalization to the gene expression of GAPDH was performed. Primer BLAST. Primer BLAST from PubMed online was used to design the primers, which were then synthesized by Sangon Biotech (China). See Table 1 for the primers used for qPCR.

\section{Western blot analysis Osteogenic protein analysis}

In 6-well plates, BMSCs were sown at a density of $3 \times 10^{5}$ cells and treated with $\mathrm{C}_{2} \mathrm{~S}$ NPs at $0,10,50$ and $100 \mu \mathrm{g} /$ $\mathrm{mL}$ for $3,7,14$, and 21 days. In addition, we detected osteogenesis regulated by autophagy induced by $\mathrm{C}_{2} \mathrm{~S}$ NPs. BMSCs were treated with $0 \mu \mathrm{g} / \mathrm{mL} \mathrm{C}_{2} \mathrm{~S}$ NPs, $5 \mathrm{mM}$ 3-MA, $10 \mathrm{nM}$ rapamycin, $50 \mu \mathrm{g} / \mathrm{mL} \mathrm{C}_{2} \mathrm{~S}$ NPs, $50 \mu \mathrm{g} / \mathrm{mL}$ $\mathrm{C}_{2} \mathrm{~S}$ NPs +3-MA, and $50 \mu \mathrm{g} / \mathrm{mL} \mathrm{C}_{2} \mathrm{~S}$ NPs + rapamycin for 7 and 14 days. After scratching the adherent cells from the culture dish and rinsing three times with icecold PBS, RIPA lysis buffer (Haimen Beotem, China) was used to extract the total protein from the cell pellet. After incubating for $30 \mathrm{~min}$ at $4{ }^{\circ} \mathrm{C}$, the specimens were subsequently centrifuged for $20 \mathrm{~min}$ at $14,000 \mathrm{~g}$. The supernatant was transferred, mixed, and boiled in SDS sample buffer $(6.8,2 \%$ SDS, 10\% glycerol, and $62.5 \mathrm{mM}$ Tris$\mathrm{HCl} \mathrm{pH).} \mathrm{The} \mathrm{BCA} \mathrm{kit} \mathrm{(Beyotime,} \mathrm{China)} \mathrm{was} \mathrm{applied} \mathrm{to}$ determine the protein concentration. After loading onto $10 \%$ SDS-PAGE gels with equal amounts of total protein, and transferring to PVDF membranes (General Electric, USA), the samples were intubated for $1 \mathrm{~h}$ at room temperature with TBS-T (25 mM Tris, $\mathrm{pH} 7.4,150 \mathrm{mM}$

\section{Table 1 Primers used for real-time PCR}

\begin{tabular}{ll}
\hline Mtot & Primer \\
\hline COL1 & 5'-CCAGCGAAGAACTCATACAG-3' \\
& 5'-GAGCGAAGGGTCAGTCAG-3' \\
OSX & 5'-GAGCAAAGTCAGATGGGTAAG-3' \\
& 5'-CACCAGGTCCAGGCAACA-3' \\
BMP2 & 5'-GAATGACTGGATCGTGGCACCTC-3' \\
& 5'-GGCATGGTTAGTGGAGTTCAGGTG-3' \\
RUNX2 & 5'-CCCAGCCACCTTACCTACA-3' \\
& 5-TATGGAGTGCTGCTGGTCTG-3' \\
GAPDH & 5'-TGTCGTGGAGTCTACTGGTG-3' \\
& 5'-GCATTGCTGACAATCTTGAG-3' \\
\hline
\end{tabular}


$\mathrm{NaCl}$, and $0.1 \%$ Tween-20) supplemented with 5\% skimmed dry milk, followed by incubation with primary antibody at $4{ }^{\circ} \mathrm{C}$ overnight. Upon 3 washes with TBS-T, goat anti-rabbit IgG HRP-linked antibodies (Beyotime, China) were incubated at an ambient temperature for $1 \mathrm{~h}$. The plaques were identified with an ECL detection kit (General Electric, USA) in accordance with the manufacturer's protocol. Incubation of protein samples at 3, 7 , and 14 days was detected with the following antibodies: anti-GAPDH (1:2000), anti-BMP2 (1:1000; Ab Cam, USA); anti-OPN (1:2000), and anti-RUNX2 (1:2000; Ab Cam, USA). To analyze the results, the relative ratio was determined using ImageJ software.

\section{Autophagy protein analysis}

Western blotting was conducted to determine the expression of molecules associated with the autophagic pathway, as described earlier. BMSCs were sown in 6-well plates at a density of $3 \times 10^{5}$ cells and then treated with $0 \mu \mathrm{g} / \mathrm{mL} \mathrm{C}_{2} \mathrm{~S}$ NPs, $5 \mathrm{mM} 3-\mathrm{MA}, 10 \mathrm{nM}$ rapamycin, $50 \mu \mathrm{g} /$ $\mathrm{mL} \mathrm{C}_{2} \mathrm{~S}$ NPs, $50 \mu \mathrm{g} / \mathrm{mL} \mathrm{C}_{2} \mathrm{~S}$ NPs $+3-\mathrm{MA}$, and $50 \mu \mathrm{g} / \mathrm{mL}$ $\mathrm{C}_{2} \mathrm{~S}$ NPs + rapamycin for 7 and 14 days. Protein extraction and SDS polyacrylamide electrophoresis were carried on as previously mentioned. Specimen protein was tested with the following antibodies: anti-GAPDH (1:2000), anti-Beclin (1:2000 Ab Cam, USA), anti-P62 (1:2000; Ab Cam, USA), and anti-LC3 (1:1000; Ab Cam USA). To analyze the results, the relative ratio was determined using ImageJ software.

\section{In vivo analysis}

Southern Medical University Animal Center (Guangzhou, China) provided the SD rats $(n=6$, weight $=250 \mathrm{~g})$. All experiments associated with animals were approved by and conducted in accordance with the regulations of the China National Ethics Committee on Animal Welfare, which issued the approval number L2018033. Experimental rats were kept in a ventilated animal chamber at a temperature of $23 \pm 1{ }^{\circ} \mathrm{C}$ and $55-65 \%$ relative humidity, under a 12-h light/dark cycle. According to the method described previously, a mouse model of renal tubular deficiency was utilized to assess the osteogenic activity of $\mathrm{C}_{2} \mathrm{~S}$ NPs [25]. Briefly, surgery was performed under general anesthesia. A 5-mm-diameter calvarial defect was generated in each SD rat. The defects received no graft in the control group and were treated with $\mathrm{C}_{2} \mathrm{~S}$ NPs in the $\mathrm{C}_{2} \mathrm{~S}$ group.

To measure the parameters of skeleton formation, intraperitoneal injections of tetracycline $(5 \mathrm{mg} / \mathrm{kg}$; Sigma-Aldrich) and calcein (25 mg/kg; Sigma-Aldrich) were dosed at 2 weeks and 1 week before sacrifice to mark newly formed bone surfaces. At week 4, 8, and 12 following implantation, the rats were sacrificed, and buffered glutaraldehyde (4\%)-glutaraldehyde (0.25\%) fixative ( $\mathrm{pH}$ 7.4) was utilized to fix the calvariae at $4{ }^{\circ} \mathrm{C}$ for 3 days, which was applied to assess bone regeneration. The samples were further analyzed using micro-CT and histological techniques.

\section{Observation of new bone formation}

Calvarial bone was collected, dehydrated (from 75\% to $100 \%$ ) with increasing ethanol concentrations, and embedded in polymethyl methacrylate (PMMA). The central region of the sagittal defect was sliced to an ultimate thickness of approximately $40 \mu \mathrm{m}$. Excitation/ emission wavelengths of 488/500-550 nm (green carbenicillin, green) and 543/580-670 nm (tetracycline, red) were labeled using a fluorescence microscope (Olympus, Japan). The marking distance between carbenicillin green and tetracycline was divided by the time interval of the marking period. Then rate of mineral adhesion was obtained. Van Gieson's picrofuchsin and Stevenel's blue dye were adopted to qualitatively observe the formation of new bone.

\section{Micro-CT evaluation of bone formation}

Micro-computed tomography (micro-CT) was utilized to investigate new bone formation at 4,8 , and 12 weeks with parameters of $8.85 \mu \mathrm{m} /$ pixel of resolution, accompanied by $50 \mathrm{kV}$ of voltage and $500 \mu \mathrm{A}$ current. The commercial software MIMICS (NRecon, USA; CTvox, USA) was used to assess a fixed global threshold of $20 \%$. The new bone volume was identified as the total volume of the $5-\mathrm{mm}$ diameter bone disc centered on the defect.

\section{Histological analysis}

After $72 \mathrm{~h}$ in $4 \%$ cis-butylene solution, all specimens were fixed and decalcified in $10 \%$ ethylenediaminetetraacetic acid (EDTA) and stored for 25 days at $4{ }^{\circ} \mathrm{C}$. After the calcium was eliminated, the skull was dehydrated, cleaned, prepared in paraffin blocks in accordance with standard histological procedures, and sliced at $5 \mu \mathrm{m}$. Dyeing of histological Sects. $(8 \mu \mathrm{m})$ for the target of interest was performed. Hematoxylin and eosin (H\&E) staining were performed thereafter. For BMP2, LC3, p-ULK1, and ULK1 immunochemical staining, the sections were stained with the following primary antibodies: anti-LC3 (1:500; Ab Cam USA), anti-BMP2 (1:500; Ab Cam USA), anti-ULK1 (1:500, Ab Cam USA), and antip-ULK1 (1:500; CST USA). Peroxidase assays were performed using the Vectastain ABC kit with DAB substrate kit. ImageJ was used to quantify the area of newly formed bone tissue.

\section{Statistical analyses}

Experimental results are displayed as the mean \pm SEM in vitro and mean $\pm S D$ in vivo of a minimum of three 
independent trials. Inter-group difference statistical significance was assessed with the GraphPad Prism (GraphPad, CA, USA) Student's $t$ test and one-way ANOVA (Tukey's multiple comparison test). " $p<0.05$ was considered statistically significant.

\section{Results}

\section{Characterization of $\mathrm{C}_{2} \mathrm{~S}$ NPs}

The TEM and SEM images of the $\mathrm{C}_{2} \mathrm{~S}$ nanoparticle samples revealed that the particles of $\mathrm{C}_{2} \mathrm{~S}$ powder had a size under $100 \mathrm{~nm}$ (Fig. 1a) and irregular shapes and surfaces (Fig. 1b). The particle size of the $\mathrm{C}_{2} \mathrm{~S}$ powder was visualized between 40 and $150 \mathrm{~nm}$ using laser diffraction, and $50 \%$ of the particles in the sample were less than $100 \mathrm{~nm}$ (Fig. 1c). The spectra of the samples were shown to be consistent with those of $\mathrm{Ca}_{2} \mathrm{SiO}_{4}$ by XRD analysis. The corresponding peak and the standard peak were matched (Fig. 1d). The mean thickness was approximately $6.0 \mathrm{~nm}$ via AFM (Fig. 1e). EDS analyses identified $\mathrm{Ca}, \mathrm{Si}$, and $\mathrm{O}$, and the atomic ratio of $\mathrm{Si}, \mathrm{O}$, and $\mathrm{Ca}$ was $1.02,60.89$, and 29.08, corresponding to $\mathrm{Ca}_{2} \mathrm{SiO}_{4}$. The sample contained $\mathrm{C}_{2} \mathrm{~S}$ NPs (Fig. 1f). The FTIR spectra (Fig. 1g) showed absorption peaks at $615,800-1000,1420$, and $3400-3700$, confirming the presence of $\mathrm{C}-\mathrm{O}, \mathrm{Si}-\mathrm{O}$ and unbound water, which are characteristic vibrations of $\mathrm{C}_{2} \mathrm{~S}$ NPs.

\section{Biocompatibility evaluation of $\mathrm{C}_{2} \mathrm{~S} \mathrm{NPs}$ Dissolution of $\mathrm{C}_{2} \mathrm{SNPs}$ in complete cell culture medium}

For the purpose of exploring the ion levels released by $\mathrm{C}_{2} \mathrm{~S}$ NPs in the extracellular fluid. the concentrations of silicon and calcium in various concentrations of complete media were assessed (Fig. 2a). The different concentrations of $\mathrm{C}_{2} \mathrm{~S}$ NPs put up dissolution after incubation for $24 \mathrm{~h}$. Along with the increased concentration of $\mathrm{C}_{2} \mathrm{~S}$ NPs, the concentration of silicon ions was found to be dramatically elevated $(p<0.05)$. However, the percentage of composition of calcium ions was not meaningfully altered with the increase in $\mathrm{C}_{2} \mathrm{~S}$ NPs. In addition, the concentration of phosphorus was significantly decreased. The maximum concentration of silica was approximately $4.48 \mu \mathrm{g} /$ $\mathrm{mL}$ at a saturation of $100 \mu \mathrm{g} / \mathrm{mL} \mathrm{C}_{2} \mathrm{~S} \mathrm{NPs}$, and the lowest silica saturation was under $0.05 \mu \mathrm{g} / \mathrm{mL}$ at a saturation of $10 \mu \mathrm{g} / \mathrm{mL} \mathrm{C}_{2} \mathrm{~S}$ NPs; at a $\mathrm{C}_{2} \mathrm{~S}$ NP concentration of $50 \mu \mathrm{g} /$ $\mathrm{mL}$, the silica concentration was approximately $1.34 \mu \mathrm{g} /$ $\mathrm{mL}$. At $10 \mu \mathrm{g} / \mathrm{mL} \mathrm{C}_{2} \mathrm{~S}$ NPs, the saturation of calcium was nearly $38.96 \mu \mathrm{g} / \mathrm{mL}$. The calcium ion concentration was $39.01 \mu \mathrm{g} / \mathrm{mL}$ when the $\mathrm{C}_{2} \mathrm{~S}$ NP concentration was $50 \mu \mathrm{g} / \mathrm{mL}$, and at $100 \mu \mathrm{g} / \mathrm{mL} \mathrm{C}_{2} \mathrm{~S}$ NPs, the concentration of calcium ions was $39.10 \mu \mathrm{g} / \mathrm{mL}$. The concentration of phosphorus was significantly decreased with increasing concentrations of $\mathrm{C}_{2} \mathrm{~S}$ NPs. The highest concentration of phosphorus was $35.02 \mu \mathrm{g} / \mathrm{mL}$ at a concentration of $10 \mu \mathrm{g} /$ $\mathrm{mL}_{2} \mathrm{~S}$ NPs, while the lowest saturation at $100 \mu \mathrm{g} / \mathrm{mL}$ $\mathrm{C}_{2} \mathrm{~S}$ NPs was $30.75 \mu \mathrm{g} / \mathrm{mL}$; at a concentration of $50 \mu \mathrm{g} /$ $\mathrm{mL}$, the phosphorus ion concentration was $33.10 \mu \mathrm{g} / \mathrm{mL}$.

\section{Uptake of $\mathrm{C}_{2} \mathrm{~S} N$ Ps by BMSCs}

One important issue suggesting a possible biological response from NPs is cellular uptake. With exposure to $\mathrm{C}_{2} \mathrm{~S}$ NPs for $6 \mathrm{~h}, 24 \mathrm{~h}, 3$ days, and 7 days, the uptake of $\mathrm{C}_{2} \mathrm{~S}$ NPs by BMSCs was observed via TEM. As shown in Fig. 2b, Additional file 1: S1a, $\mathrm{C}_{2} \mathrm{~S}$ NPs were observed both in cytoplasm and nuclei nanoparticles. Moreover, there were no significant effects of exposure to $\mathrm{C}_{2} \mathrm{~S}$ NPs on cell morphology and organelle structure in BMSCs (Fig. 2c).

\section{Cell viability and apoptosis profiles of $C_{2} S N P S$}

All experiments had cell survival rates greater than $95 \%$ (both pre and post powder exposure). The CCK-8 assay was adopted to assess cell survival in all experiments. Cell viability. Following exposure of BMSCs to $\mathrm{C}_{2} \mathrm{~S}$ NPs for $6,12,24 \mathrm{~h}$ and 7 days, no significant cytotoxicity was detected. Cells were viable at over $99 \%$ in all trial groups (Fig. 2d). With increasing concentrations, there was a slight increase in the cell viability of BMSCs, but there was no significant difference. A lactate dehydrogenase (LDH) leakage assay was performed to validate the results of the CCK-8 viability assessment (Fig. 2e, Additional file 1: $S 1 b)$. The results showed that $C_{2} S$ NPS caused no significant changes in cell membrane permeability. Apoptosis was detected by flow cytometry utilizing the FITC Annexin V Apoptosis Detection Kit. The results showed no obvious apoptosis in BMSCs treated with $\mathrm{C}_{2} \mathrm{~S}$ NPS. Approximately $95 \%$ of BMSCs in the $\mathrm{C}_{2} \mathrm{~S}$ NPs group did not undergo apoptosis (Fig. 2f, Additional file2: S2c). In the $\mathrm{C}_{2} \mathrm{~S}$ NPs group, the apoptosis rates slightly increased, but the difference between the $\mathrm{C}_{2} \mathrm{~S}$ NPS-treated group and the control group was not significant. These results indicated that BMSCs treated with different concentrations of $\mathrm{C}_{2} \mathrm{~S}$ NPs did not cause obvious cytotoxicity.

\footnotetext{
(See figure on next page.)

Fig. 1 Physicochemical characterization of $C_{2} S$ NPS. a Representative TEM image of the $C_{2} S$ NP morphology and size. $\mathbf{b}$ Representative SEM image of $C_{2}$ S NP morphology. $\mathbf{c}$ Particle size of $C_{2} S$ powder ranged from 40-150 nm in diameter by laser diffraction. $\mathbf{d}$ XRD analyses indicated that the spectrum of sample corresponded to $\mathrm{Ca}_{2} \mathrm{SiO}_{4}$. e Representative AFM image and thickness analysis of $\mathrm{C}_{2} \mathrm{~S} N \mathrm{NP}$. $\mathbf{f} \mathrm{EDS}$ analyses detected $\mathrm{Ca}$, $\mathrm{Si}$, and $\mathrm{O}$ corresponding to $\mathrm{Ca}_{2} \mathrm{SiO}_{4} \cdot \mathbf{g}$ Functional groups of $\mathrm{C}_{2} \mathrm{~S}$ NPs identified by the FTIR spectrum showed the presence of $\mathrm{C}-\mathrm{O}$, Si-O and unbound water
} 
a
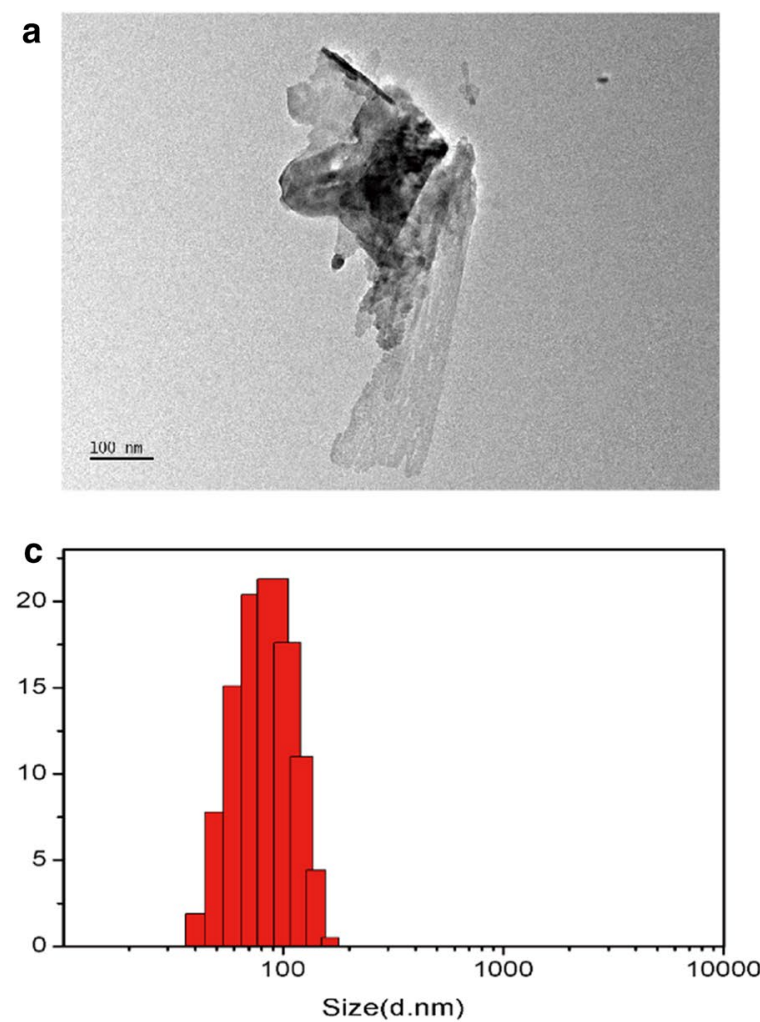

e

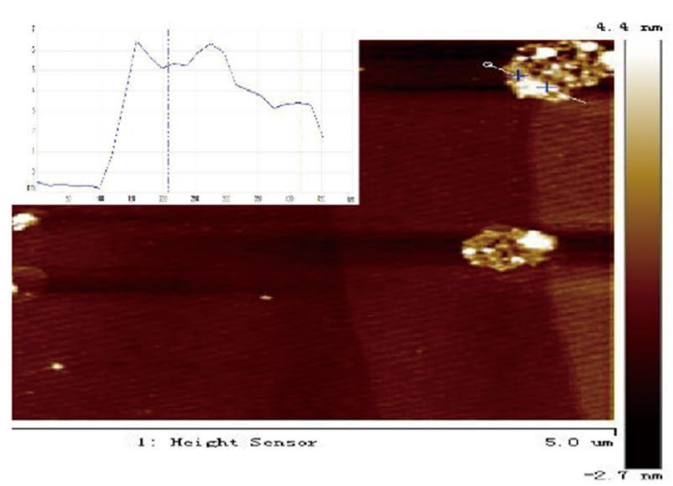

b

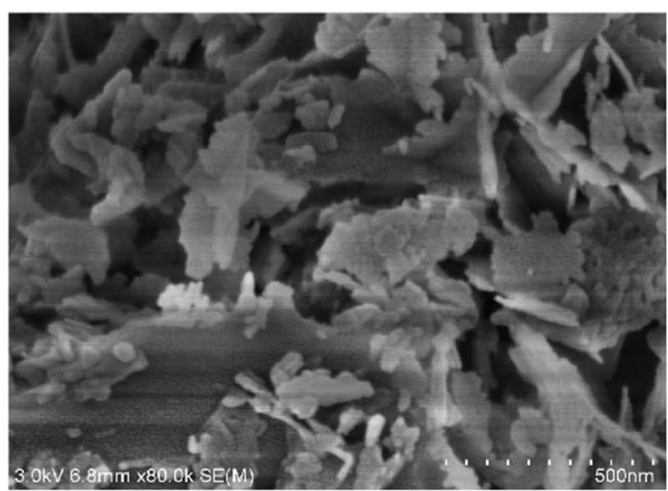

d

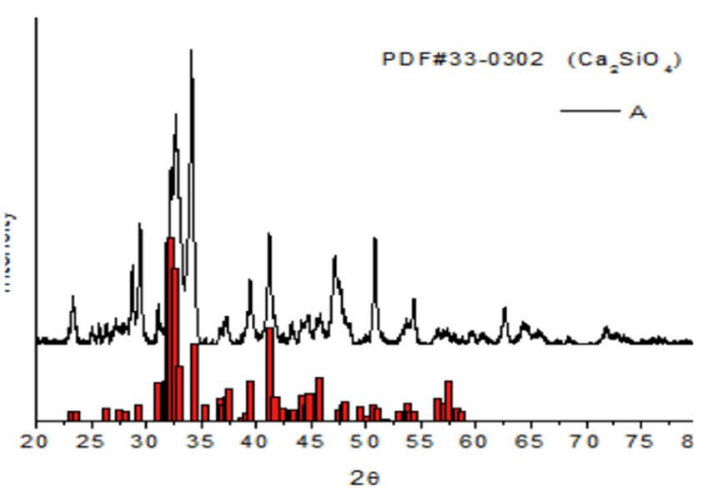

f

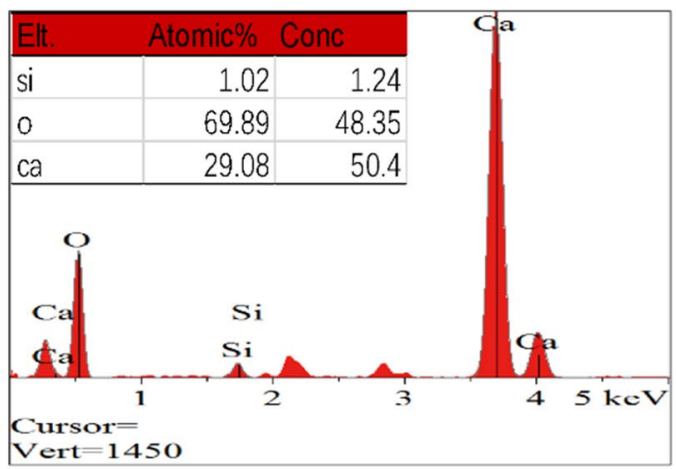

g

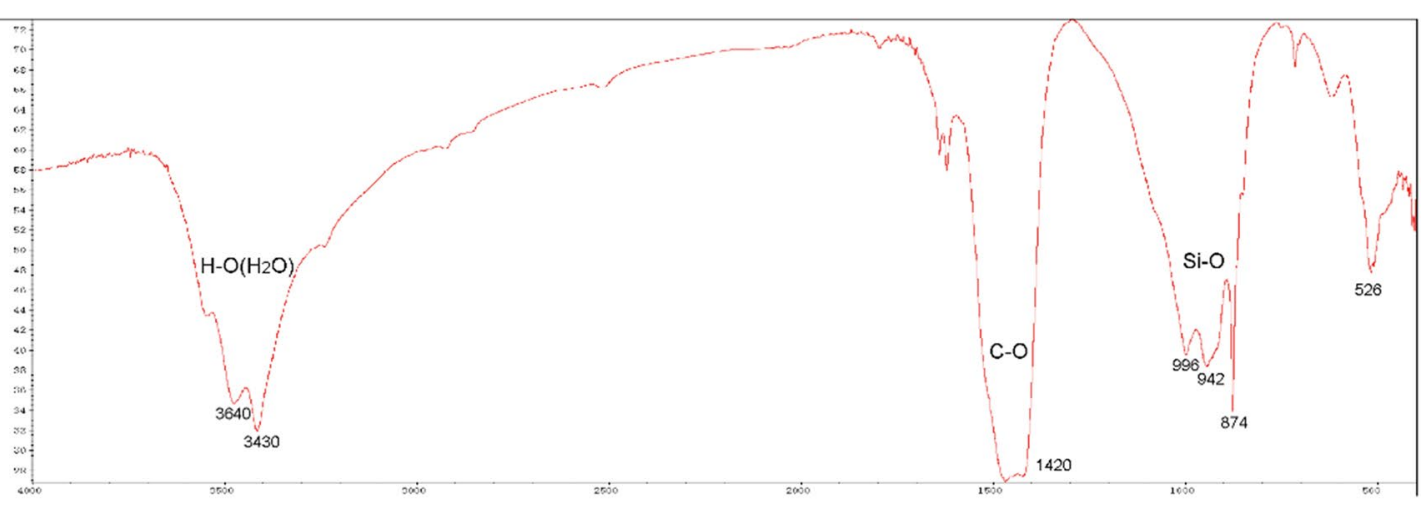




\section{Osteogenic effect of $\mathrm{C}_{2} \mathrm{~S}$ NPs}

$\mathrm{C}_{2} \mathrm{~S}$ NPs promote cell proliferation of BMSCS

Cell cycle profiling (Fig. 3a) illustrated that the proportion of cells in G1 phase dropped from $66.58 \%$ to $48.48 \%$ and $46 \%$ in cells treated with $50 \mu \mathrm{g} / \mathrm{mL}$ and $100 \mu \mathrm{g} / \mathrm{mL}$ $\mathrm{C}_{2} \mathrm{~S}$ NPs, whereas the proportion of cells in $\mathrm{S}$ phase increased significantly from $24.74 \%$ to $48.09 \%$ and $45.53 \%$ $(p<0.05)$.The cell cycle results showed that BMSCs incubated with $\mathrm{C}_{2} \mathrm{~S}$ NPs promoted cell cycle changes from $\mathrm{G} 1$ phase to $\mathrm{S}$ phase, which indicated an increase in cell division. The CCK-8 assay was utilized to determine cell proliferation, which confirmed the increasing proliferation of BMSCs treated with $\mathrm{C}_{2} \mathrm{~S}$ NPs. As shown in Fig. 3b, BMSCs were exposed to $\mathrm{C}_{2} \mathrm{~S}$ NPs for 2,3 , and 7 days, and the proliferating cells in each group continued to increase with increasing concentrations of $\mathrm{C}_{2} \mathrm{~S}$ NPs. At each time point, we found significantly increased cell proliferation when BMSCs were treated with $50 \mu \mathrm{g} / \mathrm{mL}$ and $100 \mu \mathrm{g} /$ $\mathrm{mL} \mathrm{C}_{2} \mathrm{~S}$ NPs $(p<0.05)$. However, BMSCs treated with $10 \mu \mathrm{g} / \mathrm{mL} \mathrm{C}_{2} \mathrm{~S}$ NPs showed no significant increase in cell proliferation $(p>0.05)$.

\section{Mineralization of BMSCs treated with $\mathrm{C}_{2} S \mathrm{NPS}$}

For the exploration of BMSCs early and late osteogenic cell differentiation, ALP activity was investigated. ALP is an important early-stage osteoblastic marker, and its activity was evaluated following the incubation of cells with osteobd)last-inducing conditional media and different concentrations of $\mathrm{C}_{2} \mathrm{~S}$ NPs for 7, 14, and 21 days. As shown in Fig. 3c, there was no significant difference in ALP activity between the $\mathrm{C}_{2} \mathrm{~S}$ NP treatment groups and the control group after 7 and 14 days $(p>0.05)$. ALP activity was increased slightly with increasing $\mathrm{C}_{2} \mathrm{~S} N \mathrm{NP}$ concentrations after culture for 4 days $(p>0.05)$. These results indicated that $\mathrm{C}_{2} \mathrm{~S}$ NPs did not promote BMSC ALP expression. It was also an important indicator of late differentiation of osteoblasts, demonstrating that osteoblasts had developed into organic matter for bone formation by entering the mineralization phase. The formation of mineralized nodules (Fig. 3d) was utilized to assess the effects on the late osteogenesis of BMSCs of $\mathrm{C}_{2} \mathrm{~S}$ NPs. Mineralized nodules were observed by ARS staining at 14 and 21 days after osteogenic differentiation. The accumulation of mineral matrix deposition increased as the color of the stain darkened and thickened with increasing concentration of $\mathrm{C}_{2} \mathrm{~S}$ NPs. These results indicated that $\mathrm{C}_{2} \mathrm{~S}$ NPs could facilitate mineralization.

\section{The effect of $C_{2} S N P s$ on the expression of osteogenic genes and proteins}

mRNA expression of the osteogenesis-regulated genes COLI, OSX (Osterix), RUNX2, and BMP2 was identified by RT-PCR. On the third day, COLI and OSX were significantly increased after treatment with 10,50 , and $100 \mu \mathrm{g} / \mathrm{mL} \mathrm{C}_{2} \mathrm{~S}$ NPs. BMP2 and RUNX2 mRNA expression significantly increased at 7 and 14 days (Fig. 3e). We identified the protein expression related to osteoblast differentiation, and the results showed that $\mathrm{C}_{2} \mathrm{~S} N P$ stimulation accelerated osteoblast differentiation of BMSCs. Increased protein expression of $\beta$-catenin, Runx 2 , and BMP2 was detectable at days $3,7,14$, and 21 , Axin1 expression was increased at days 3,7 , and 14 , and OPN expression was increased at days 7 and 14; At day 21, the differences in protein expression began to decline (Fig. 3f).

\section{$\mathrm{C}_{2}$ S NPs stimulated autophagy in BMSCs}

TEM was utilized to study the subcellular effect of $\mathrm{C}_{2} \mathrm{~S}$ in BMSCs. Our TEM images revealed considerable autolysosomes and autophagosomes in BMSCs treated with $\mathrm{C}_{2} \mathrm{~S}$ NPs compared with the control BMSCs (Fig. 4a, Additional file 1: S1A). Immunofluorescence results also confirmed the occurrence of autophagy in BMSCs. LC3 accumulation was detected with a confocal microscope. Treatment of $\mathrm{C}_{2} \mathrm{~S}$ NPs resulted in a marked increase in FITC-labeled LC3B formation. We observed that LC3B formation increased under $\mathrm{C}_{2} \mathrm{~S}$ NPs treatment at 3,6 , and $12 \mathrm{~h}$ (Fig. 4b-e). To explore whether autophagy could be induced by $\mathrm{C}_{2} \mathrm{~S}$ NPs in BMSCs, we next detected changes in several autophagy-related proteins. A known biomarker of autophagosome formation is the transformation of the mature form of LC3 $\beta$-I into the LC3 $\beta$-II form associated with cleaved/lapidated autophagosome, while P62 is a biomarker of autolysis degradation. As presented in Fig. 4f, g, osteoblast induction dramatically increased the conversion of LC3 $\beta$-II from LC3 $\beta$-I according to Western blotting, and the autophagy cargo P62 was decreased upon autophagy activation in $\mathrm{C}_{2} \mathrm{~S}$ NP-treated

\section{(See figure on next page.)}

Fig. 2 Biocompatibility evaluation of BMSCs exposed to $C_{2} S$ NPs $(0,10,50,100 \mu \mathrm{g} / \mathrm{mL})$. a ICP-MS exploration of ion levels released from $C_{2} S$ NPs in extracellular fluid for $24 \mathrm{~h}$. $\mathbf{b}$ Uptake of $\mathrm{C}_{2} S \mathrm{NPs}$ by BMSCs was observed via TEM at $6 \mathrm{~h}$. c Cellular morphology and structures of cell organelles were observed by rhodamine-phalloidin (Green) and DAPI (Blue) staining of BMSCs at different times points (6, 12, and $24 \mathrm{~h}$ ), scale bar $20 \mu \mathrm{m}$. d Cell viability was evaluated using CCK-8 assays at different times points $(6,12$, and $24 \mathrm{~h})$. e The levels of LDH release were detected in BMSCS post-treatment with $\mathrm{C}_{2}$ S NPs for 6, 12, and $24 \mathrm{~h}$; $\mathbf{f}$ Cells were stained with Annexin V-FITC and PI and analyzed by flow cytometry. Quantification of the cell early and total apoptosis ratio is shown below on the right. Values are expressed as the mean $\pm \operatorname{SEM} n=3 .{ }^{*} p<0.05,{ }^{* *} p<0.01,{ }^{* * *} p<0.001$ compared with the control group 


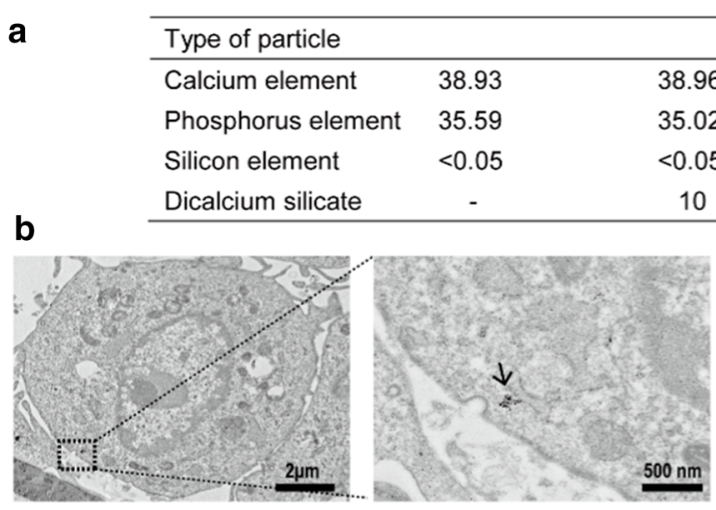

\begin{tabular}{cl} 
Concentration $(\mu \mathrm{g} / \mathrm{mL})$ & \\
\hline 39.01 & 39.10 \\
$33.10^{\star \star}$ & $30.75^{\star \star \star}$ \\
$1.34^{\star \star \star}$ & $4.48^{\star \star \star}$ \\
50 & 100
\end{tabular}
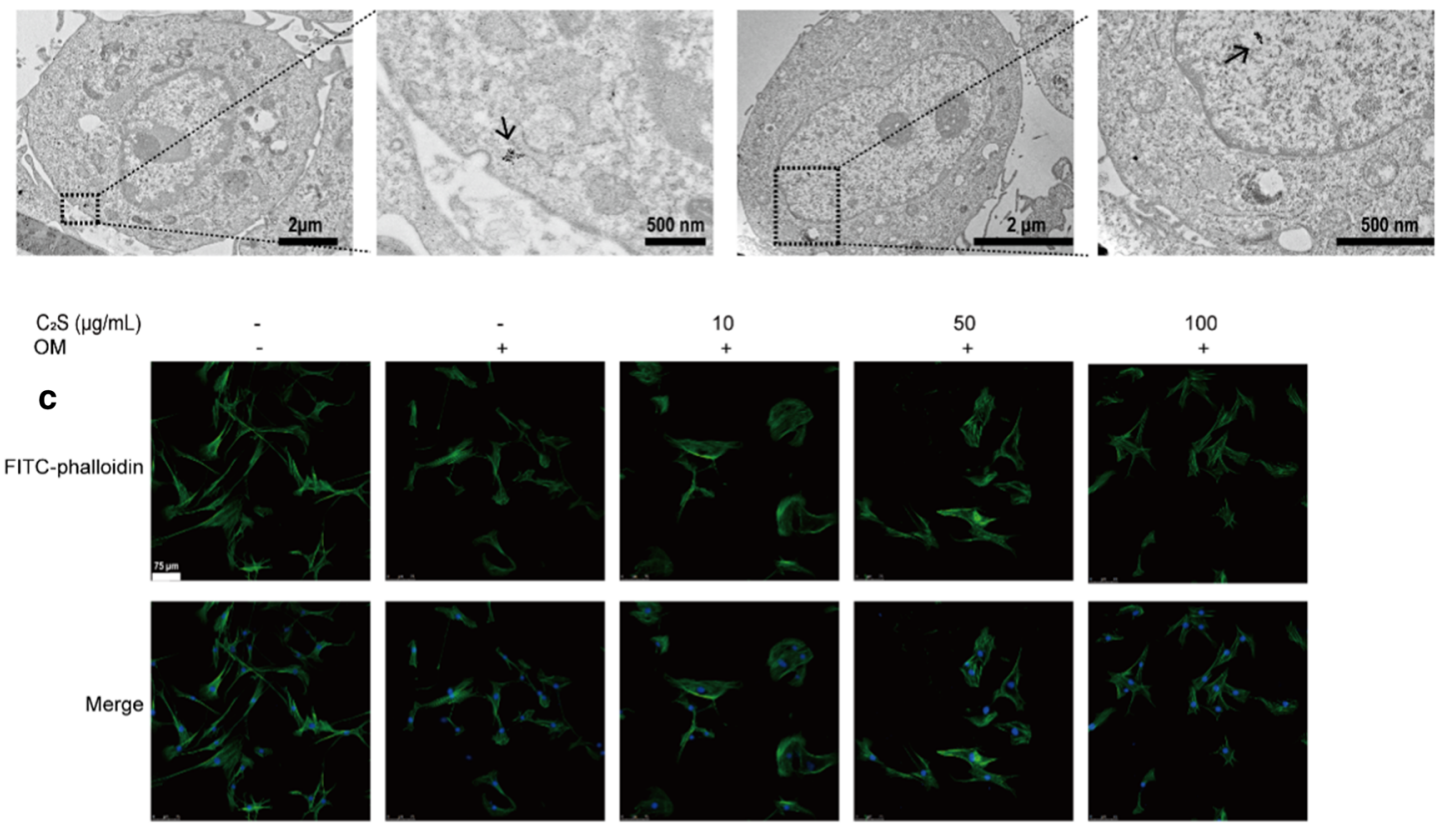

d
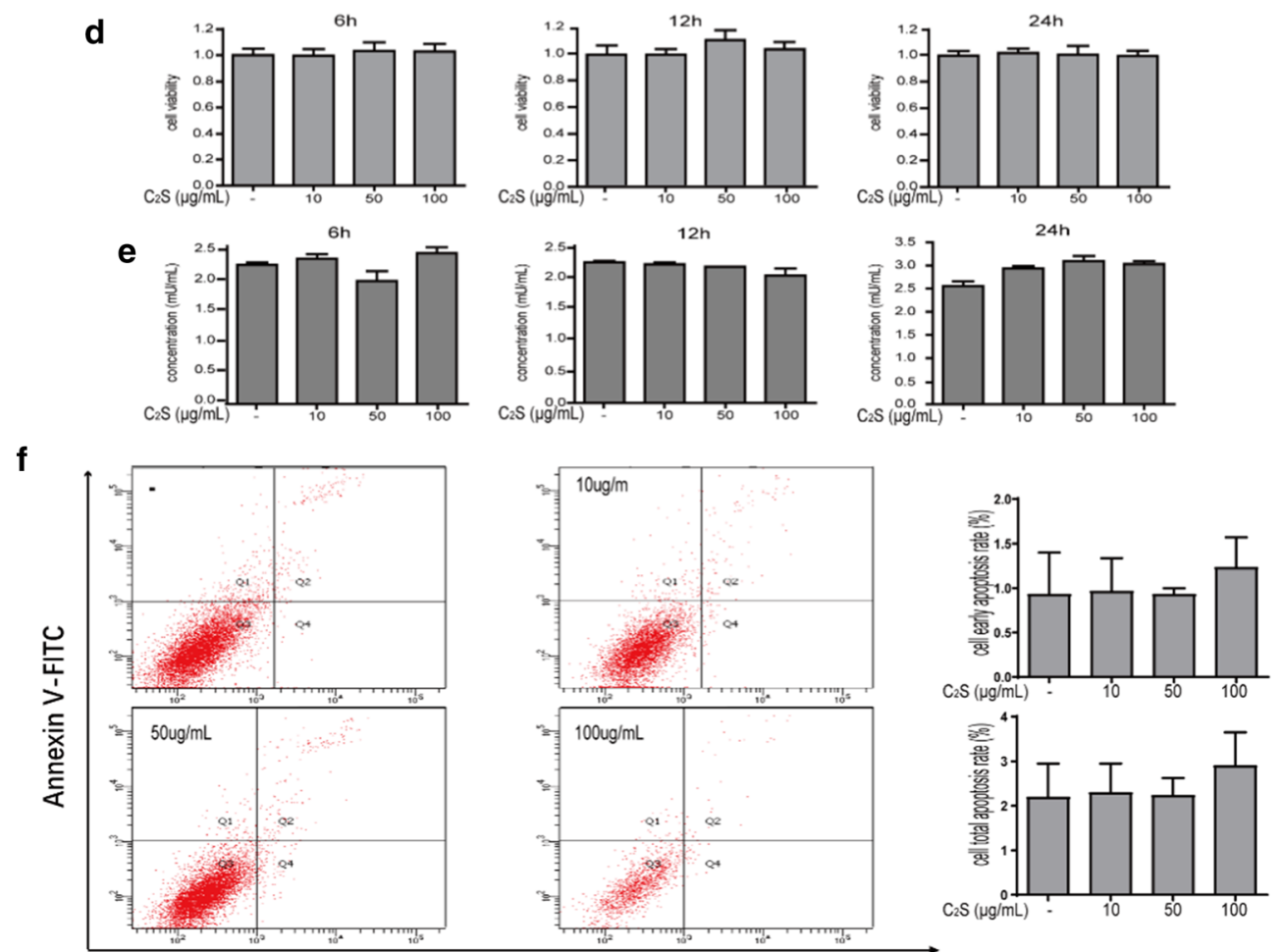

PI-A 
cells, indicating increased autophagic activity. Treatment of BMSCs with $\mathrm{C}_{2} \mathrm{~S}$ NPs for 3, 6, and $12 \mathrm{~h}$ resulted in a strong increase in LC3 $\beta$-II. Likewise, we detected an increase in beclin1, which also had a critical function in the autophagy configuration.

\section{$\mathrm{C}_{2} \mathrm{~S} \mathrm{NPs} \mathrm{promote} \mathrm{osteogenesis} \mathrm{through} \mathrm{the} \mathrm{autophagy}$ effect}

We then examined whether $\mathrm{C}_{2} \mathrm{~S}$ NPs could continuously induce autophagy. The Western blot results revealed increased protein expression associated with autophagy. $\mathrm{C}_{2} \mathrm{~S}$ NPs promoted activation of autophagy, which was manifested by elevated rates of conversion from LC3-I to LC3-II, enhanced generation of serine/threonine protein kinase ULK1 and beclin, and reduced expression of P62 at days 7 and 14 compared with the control group (Fig. 5a). To explore whether autophagy participates in regulating osteogenic differentiation induced by $\mathrm{C}_{2} \mathrm{~S}$ NPs, the autophagy inhibitor 3-MA and the activator rapamycin were applied. The 3-MA significantly inhibited $\mathrm{C}_{2} \mathrm{~S}$ NP-induced autophagy activation, while rapamycin enhanced autophagy (Fig. 5b). We first evaluated the acceleration of osteoblast differentiation in response to 3-MA and rapamycin treatment. Compared with the control treatment, 3-MA reduced while rapamycin accelerated osteoblast differentiation of BMSCs. Following culture with 3-MA and rapamycin treatment, ALP and alizarin red staining were applied to determine osteoblast differentiation. As illustrated in Fig. 5c, NBT-formazan stained with BCIP/NBT working fluid was markedly elevated in the rapamycin group, whereas the enhancement of osteogenic differentiation induced by $\mathrm{C}_{2} \mathrm{~S}$ NP incorporation was reduced in the 3-MA group at 7, 14, and 21 days after 3-MA pretreatment. Correspondingly, while autophagy occurred, the alizarin red staining results indicated the formation of more mineralized nodules with autophagy, and 3-MA inhibited the formation of mineralized nodules (Fig. 5d). The levels of Runx2 and BMP2, which are markers of osteogenesis, could be significantly reduced by pretreatment with 3-MA prior to osteogenic induction according to the Western blot results. In addition, the activation of autophagy triggered by $\mathrm{C}_{2} \mathrm{~S}$ NPs was markedly inhibited by 3-MA (Fig. 5e, f). Conversely, pretreatment with the autophagy activator rapamycin elevated the levels of Runx2 and BMP2 (Fig. 5e, f). These findings suggested that osteogenic differentiation could be enhanced by autophagy. $\mathrm{C}_{2} \mathrm{~S}$ NP administration regulated autophagic activation. The role of autophagy in these procedures is being investigated further in our current research. As revealed in Fig. 5e, f, $\mathrm{C}_{2} \mathrm{~S}$ NP treatment significantly decreased the $\mathrm{p}-\mathrm{mTOR} / \mathrm{mTOR}$ ratio and increased the p-ULK1/ULK1 ratio, which is a typical autophagy activity mediator. Nevertheless, $\mathrm{C}_{2} \mathrm{~S}$ NPs also enhanced $\beta$-catenin, together with P62 degradation. These results provided evidence that autophagy could be mediated by $\mathrm{C}_{2} \mathrm{~S}$ NPs through suppression of mTOR and promotion of ULK1 activation. In summary, we concluded that BMSC differentiation could be mediated by $\mathrm{C}_{2} \mathrm{~S}$ NPs administration through activation of mTOR/ ULK1-induced autophagy (Fig. 6).

\section{$\mathrm{C}_{2} \mathrm{~S}$ NPs promote osteogenesis through the autophagy effect in vivo}

We employed an osteoclast-deficient model to investigate the role of autophagy in osteoclast differentiation. No animal deaths or significant body weight changes were caused by $\mathrm{C}_{2} \mathrm{~S}$ NPs, and HE staining revealed no significant inflammatory cell infiltration in the defect area (Additional file 2: Fig. S2b, c), indicating no obvious toxicity. Compared with the control group, $\mathrm{C}_{2} \mathrm{~S}$ NPs led to abundant bone formation, as evidenced by the elevated ratio of bone volume to tissue volume (BV/TV). It can be concluded that much more new bone formed in (Fig. 6) defects implanted with $\mathrm{C}_{2} \mathrm{~S}$ NPs compared with the control subjects through Micro-CT reconstruction (Fig. 7a). Quantitative analysis showed that the relative new bone mass was considerably greater in the $\mathrm{C}_{2} \mathrm{~S}$ NPs group than the control group (Fig. 7b). Van Gieson's picrofuchsin and Stevenel's blue staining were performed to evaluate the bone formation (Additional file 2: Fig. S2d), and double-labeling immunofluorescence staining (Fig. 7c, d) was performed. The MAR was calculated as the area between the centers of the red band (tetracycline) and the green band (calcein). As shown in Fig. 7f, markedly higher MAR was observed at 4,8 , and 12 weeks in the $\mathrm{C}_{2} \mathrm{~S}$ NP group compared with the control group $(\mathrm{n}=6, p<0.05)$.

\footnotetext{
(See figure on next page.)

Fig. 3 Osteogenic effect of $C_{2} S N P(0,10,50,100 \mu \mathrm{g} / \mathrm{mL})$ nanoparticles in vitro. a The cell cycle was detected by flow cytometry. BMSCs were incubated with 50 and $100 \mu \mathrm{g} / \mathrm{mL} C_{2}$ S NPs for $24 \mathrm{~h}$. b Cell proliferation was evaluated using CCK-8 assays at different times points (2, 3, and 7 days). ALP activity (c) and the formation of mineralized nodules (d) were detected by BCIP/NBT and Alizarin red $S$ staining accompanied by increasing concentrations of $C_{2} S$ NPs at different time points (7, 14, 21 days). e The total mRNA levels of COLI, OSX (Osterix), RUNX2, and BMP2 in BMSCs treated with $C_{2}$ S NPs $(0,10,50,100 \mu \mathrm{g} / \mathrm{mL})$ at different time points $(3,7,14,21$ days) was detected by RT-PCR. f The total protein levels of $\beta$-catenin, RUNX2, BMP2, OPN and AXIN1 were detected by western blotting, and the cells were treated as in (e). Densitometry data were normalized to GAPDH. The relative optical density was analyzed using ImageJ software (below). Values are expressed as the mean $\pm \operatorname{SEM} . n=3 .{ }^{*} p<0.05,{ }^{* *} p<0.01$, ${ }^{* * *} \mathrm{p}<0.001$. Compared with the control group
} 


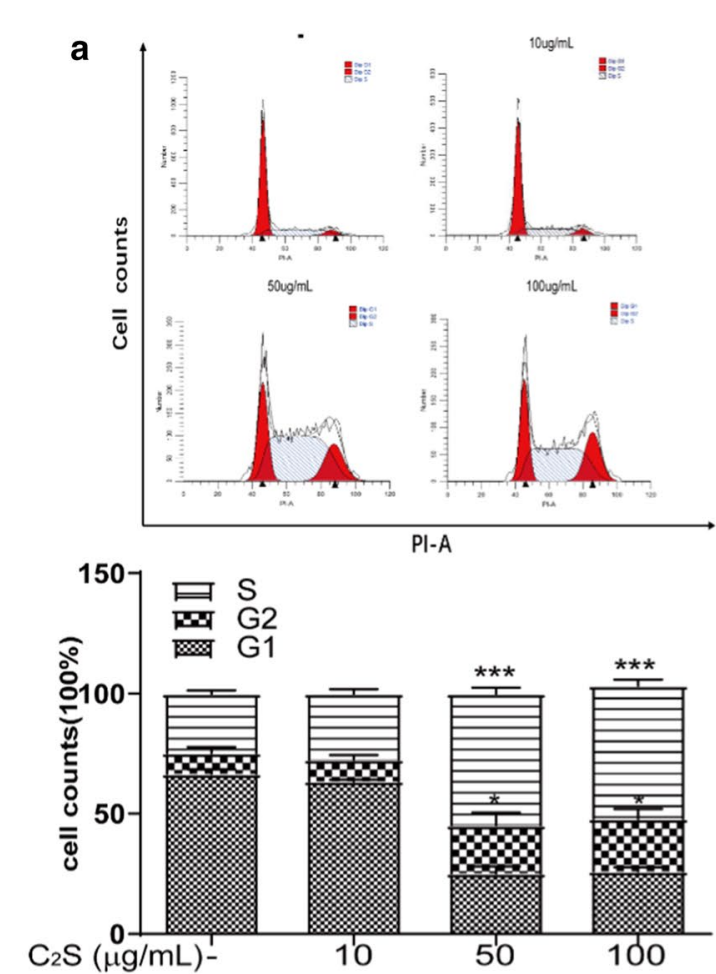

C
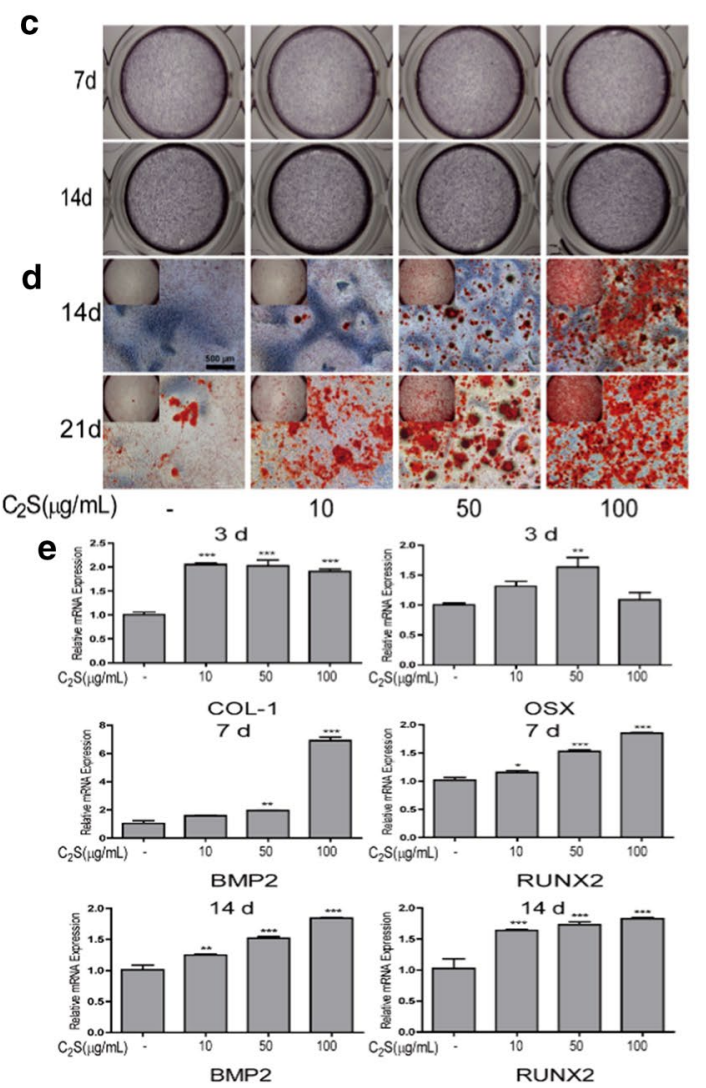
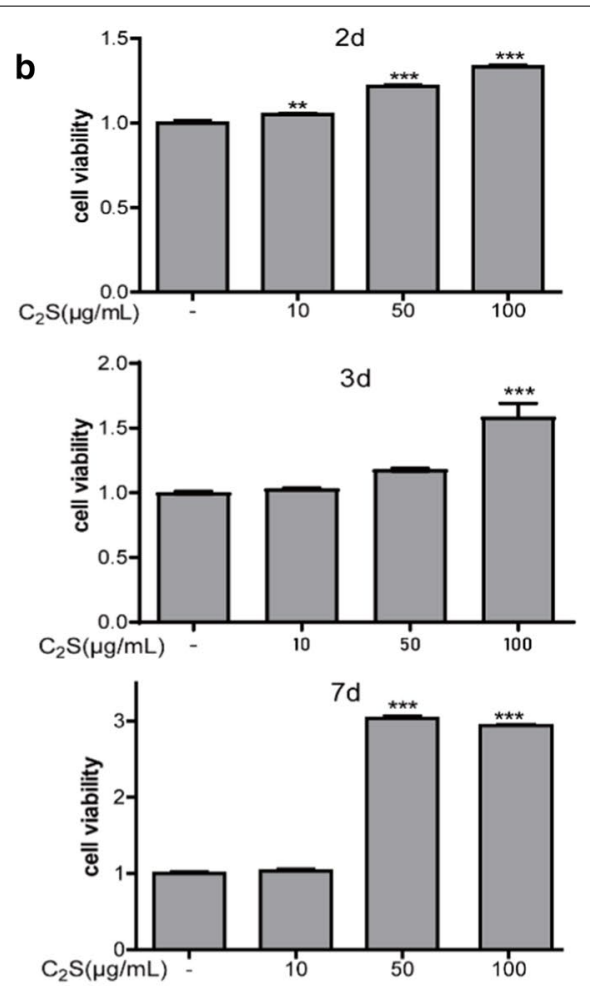

f

$\begin{array}{cccccccccccccccc}\mathrm{C}_{2} \mathrm{~S}(\mu \mathrm{g} / \mathrm{mL}) \cdot & 10 & 50 & 100 & \cdot & 10 & 50 & 100 & \cdot & 10 & 50 & 100 & \cdot & 10 & 50 & 100\end{array}$

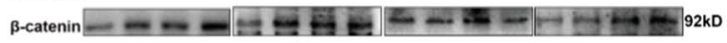

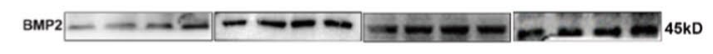

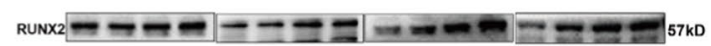

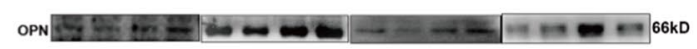

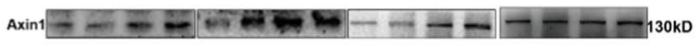

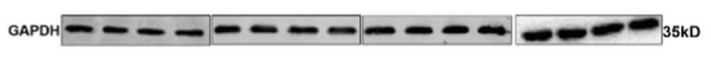

3d

$14 d$

$3 d$
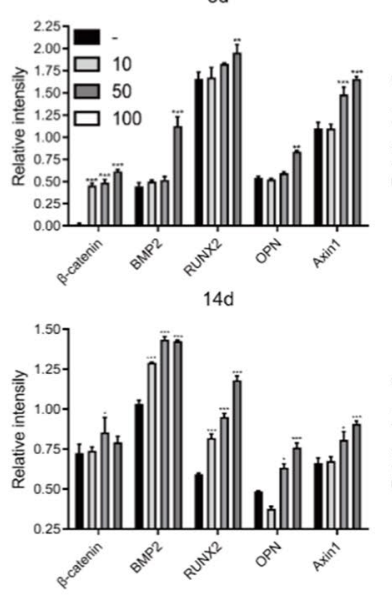
Furthermore, BMP2 immunohistochemical staining of histological sections revealed elevated bone matrix deposition and increased expression of osteogenic markers in the $\mathrm{C}_{2} \mathrm{~S}$ NPs group, suggesting a significantly enhanced activating effect of $\mathrm{C}_{2} \mathrm{~S}$ NPs on osteogenic cell differentiation (Fig. 7e, f). $\mathrm{C}_{2} \mathrm{~S}$ NPs facilitated the osteogenic process of adherent cells in vivo, which was consistent with in vitro experimental results. With the aim of validating whether the boosted activation of autophagy was attributed to bone formation, we assayed autophagy using immunohistochemical methods. The $\mathrm{C}_{2} \mathrm{~S}$ NPs had a significant promoting effect on the activation of autophagy base don ULK, LC3, and p-ULK1 staining. The results showed that the number of cells positively stained for LC3, ULK1, and p-ULK1 was greater in the $\mathrm{C}_{2} \mathrm{~S}$ NPs treatment group than the control group (Fig. 7e, f). This result is consistent with the activation of autophagy by $\mathrm{C}_{2} \mathrm{~S}$ NPs, which activated the expression of ULK1 in the calvaria defect area. These observations indicated that $\mathrm{C}_{2} \mathrm{~S}$ NPs could promote osteogenesis and mineralization by activating autophagy in the bone defect area.

\section{Discussion}

Dicalcium silicate is an amorphous silicate-based material that is a component of bioactive glasses, has good biocompatibility, and can form a chemical bond with bone tissue; therefore, it is often used in bone substitute materials, artificial bone dust, and potential realistic materials for dental implants and orthopedic treatments $[4,26-28]$. Because it is composed of natural minerals, it has a wide range of sources and is easy to obtain, so it is a very economical material. Due to its good biological activity, dicalcium silicate is considered a bioactive material with good application prospects.

Nanomaterials such as silica nanoparticles are often used in biomaterials due to their sizable specific surface area, biocompatible capacity, stability, and outstanding optical and electrical characteristics[29, 30]. Our study showed that dicalcium silicate nanoparticles $\left(\mathrm{C}_{2} \mathrm{~S}\right.$ NPs $)$ are irregularly shaped nanoparticles with a hydrated particle size of approximately $100 \mathrm{~nm}$; therefore, they have a large specific surface area. $\mathrm{C}_{2} \mathrm{~S}$ NPs can release a small number of silicon ions in complete culture medium.

In addition to these physicochemical properties, $\mathrm{C}_{2} \mathrm{~S}$ NPs have good cytocompatibility. Previous studies have shown that most nanoparticles, such as silica-based nanoparticles, enter cells by endocytosis [16, 31]. Our TEM results also revealed that $\mathrm{C}_{2} \mathrm{~S}$ NPs could be ingested by BMSCs and enter the cytoplasm and nucleus, where they further produce a series of biological effects. However, we did not observe an obvious vesicle structure around the nanoparticles Thus, we speculate that $\mathrm{C}_{2} \mathrm{~S}$ NPs first adhered to the cell membrane, and then the $\mathrm{C}_{2} \mathrm{~S}$ NPs nanoparticles were internalized and encircled by regions of the plasma membrane, growing within the cell and forming vesicles consisting of absorbed $\mathrm{C}_{2} \mathrm{~S}$ nanoparticles. The EDS results showed that the $\mathrm{C}_{2} \mathrm{~S}$ NPs contained calcium, silicon, and other biologically active groups that could promote proliferation and BMSC osteogenic differentiation in vitro and promote the formation of new bone in the bone defect area in vivo. The results of a previous study are consistent with our hypothesis, which found that the silicon component could be released from bioactive glass implants, mediating the generation of a hydroxyapatite layer containing a calcium-deficient surface that further interacts with collagen fibrils of damaged bone and subsequently allows the bioactive glass to bond to the surrounding tissue [32]. In our research, BMSCs treated with $\mathrm{C}_{2} \mathrm{~S}$ NPs could promote mineralization and osteogenic differentiation and upregulate the osteogenic genes OSX, COL1, RUNX2, BMP2, and OPN, as well the osteogenic proteins Runx2, BMP2, OPN. Interestingly, however, $\mathrm{C}_{2} \mathrm{~S}$ NPs did not promote the expression of ALP in BMSCs compared with the control group. This result is different from a previous study that found that treatment of BMSCs with silica-based nanomaterials could promote the expression of ALP [32, 33]. The difference may be due the use in our control group of osteoblast-inducing conditional medium, as well as dicalcium silicate nanoparticles instead of dicalcium silicate extract. ALP expression is promoted by osteoblast-inducing conditional medium, and $\mathrm{C}_{2} \mathrm{~S}$ NPs do not further promote ALP expression under these conditions. In addition, bone formation may be facilitated by the characteristics of the particles themselves rather than by ions in the solution. $\mathrm{C}_{2} \mathrm{~S}$ NPs may provide an ingredient for osteogenic mineralization, directly promoting the mineralization of BMSCs, rather than promoting the deposition of collagen by activating the expression of ALP and then promoting the mineralization of BMSCs [34].

\footnotetext{
(See figure on next page.)

Fig. $4 \mathrm{C}_{2}$ S NPs stimulate autophagy in BMSCs (a) TEM observations of BMSCs following treatment with $50 \mu \mathrm{g} / \mathrm{mL} \mathrm{C}_{2} S$ NPs for $24 \mathrm{~h}$. Distinct autophagic vacuoles (black arrows) were denoted in the enlarged images (lower) from the dash line squares. b-d BMSCs were treated with $C_{2} S$ NPs $(0,10,50,100 \mu \mathrm{g} / \mathrm{mL})$ for 3,6 , and $12 \mathrm{~h}$. FITC-labeled LC3 was observed under a fluorescence microscope. e The fluorescence intensity ratio was analyzed using ImageJ software (below). f total protein levels of Beclin, P62, and LC3(LC3II/LC3I) detected by western blot analysis, treating the cells as in (d). $g$ Densitometry data were normalized to GAPDH. The relative optical density was analyzed using ImageJ software. Values are expressed as the mean $\pm S E M, n=3 .{ }^{*} p<0.05,{ }^{* *} p<0.01,{ }^{* * *} p<0.001$ compared with the control group
} 


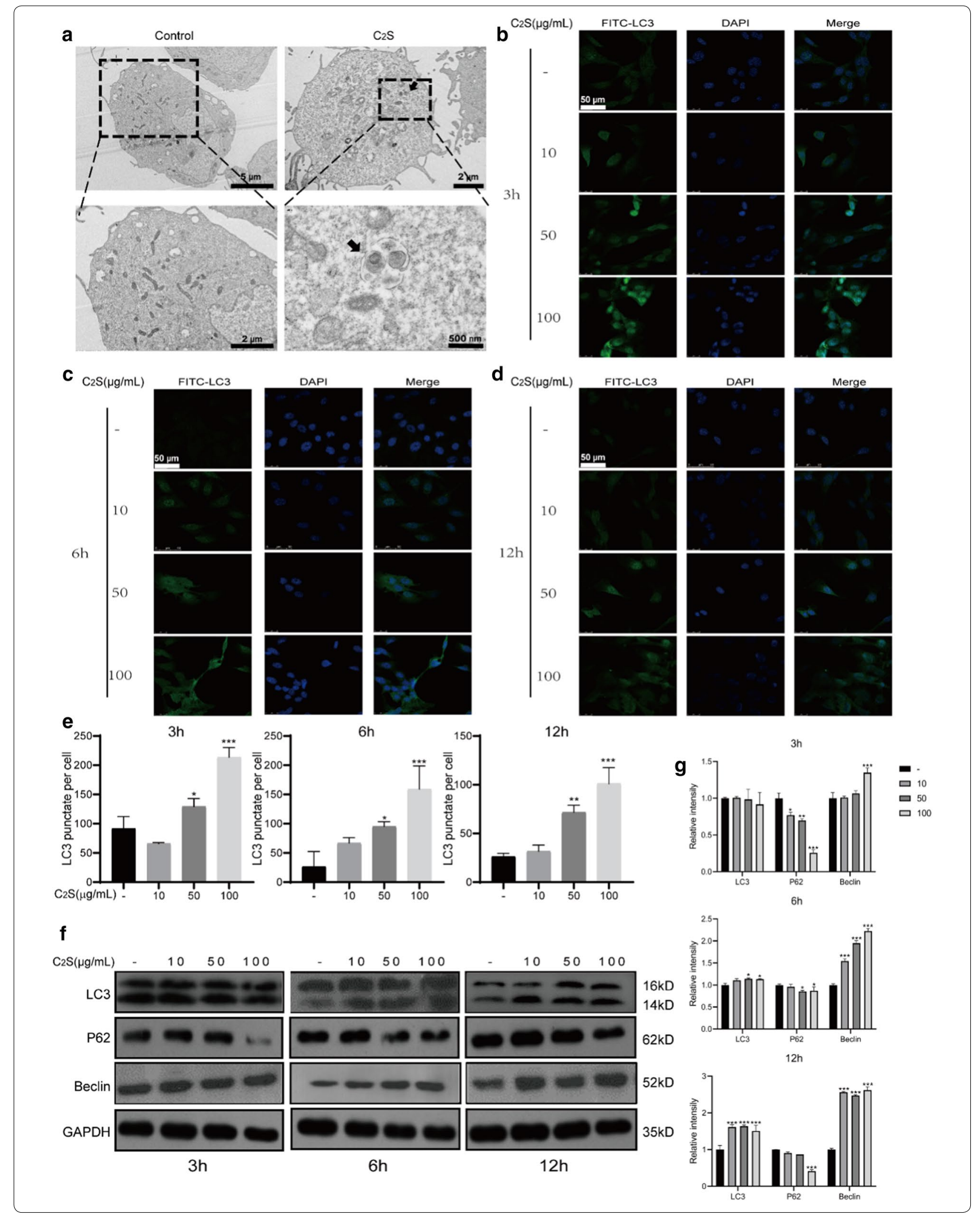


In vivo, we found that mice treated with $\mathrm{C}_{2} \mathrm{~S}$ NPs showed more new bone generation in the bone defect area than the control group. The potential mechanism by which $\mathrm{C}_{2} \mathrm{~S}$ NPs promote osteogenic differentiation and mineralization in vitro and in vivo was examined, We found that $\mathrm{C}_{2} \mathrm{~S}$ NPs could activate autophagy in BMSCs. Previous studies have found that autophagy plays an important role in osteogenic differentiation. The balance of autophagy appears to be vital for efficient MSC differentiation and function. Therefore, we investigated whether $\mathrm{C}_{2} \mathrm{~S}$ NPs could promote osteogenic mineralization by activating autophagy [14]. Our TEM results revealed that $\mathrm{C}_{2} \mathrm{~S}$ NPs could be taken up by cells. Previous studies have shown that nanomaterials can be taken up by cells and then combine with some proteins to form a structure called a protein crown. Protein crowns may be considered a misfolded protein. They are then further encapsulated and degraded by autophagosome encapsulation [35]. Next, the autophagosome binds to the lysosome to form an acidic environment, and the acidic environment of the autolysosome can promote $\mathrm{C}_{2} \mathrm{~S} N \mathrm{NP}$ release of calcium and silicon to promote biomineralization [36]. Our study found that $\mathrm{C}_{2} \mathrm{~S}$ NPs could activate the expression of LC3, as well as beclin, Atg3, and Atg7, while degrading P62. In vivo experiments also confirmed the occurrence of autophagy, and the results of immunohistochemistry showed that the expression of LC-3 was upregulated in the defect area of the $\mathrm{C}_{2} \mathrm{~S}$ NPs group compared with the control group. Thus, the $\mathrm{C}_{2} \mathrm{~S}$ NPs could promote autophagy without hindering the progression of autophagic flow and be degraded by autophagy. Autophagy can degrade damaged organelles and foreign bodies to form phosphate, which is secreted into the cytoplasm to provide an ingredient for and promote biomineralization [37].

To verify whether $C_{2} S$ NPs could promote osteogenesis and biomineralization by activating autophagy, autophagic activator rapamycin and the autophagy inhibitor 3-MA were used to activate and inhibit autophagy, respectively. We then observed indicators of osteogenic differentiation and biomineralization of BMSCs. We found that both the activator group and the $\mathrm{C}_{2} \mathrm{~S}$ NPs group showed increased expression of osteogenesisrelated genes and proteins and promotion of mineralization and osteogenic differentiation. In the inhibitor group and inhibitor plus $\mathrm{C}_{2} \mathrm{~S}$ NPs group, a downregulation of osteogenesis-related genes and proteins was observed, but compared with the inhibitor alone group, osteogenesis was induced in the inhibitor plus $\mathrm{C}_{2} \mathrm{~S}$ NPs group, and the expression of genes and proteins related to osteogenesis was increased. These findings indicate that $\mathrm{C}_{2} \mathrm{~S}$ NPs can improve the adverse effects of autophagy inhibition on osteogenic differentiation. The above experiments demonstrate that $\mathrm{C}_{2} \mathrm{~S}$ NPs can promote osteogenic differentiation and biomineralization by promoting autophagy.

The signaling pathway that activates autophagy to promote osteogenesis was examined. AMPK is a signaling pathway that is involved in energy metabolism and has also been found to be involved in osteogenic differentiation. mTOR and ULK1, which are downstream of the AMPK pathway, are closely related to autophagy [38]. Studies have found that AMPK can directly or indirectly inhibit mTOR activation of the ULK1 pathway, while the $\mathrm{Wnt} / \beta$-catenin pathway has been found to be related to osteogenic differentiation. We speculated that $\mathrm{C}_{2} \mathrm{~S}$ NPs could activate autophagy through activation of the AMPK/ULK1 pathway and then activate the Wnt/ $\beta$ catenin pathway to promote osteogenesis [39]. We verified the expression of related proteins in this pathway by Western blotting after coculture of $\mathrm{C}_{2} \mathrm{~S}$ NPs and BMSCs. We found that $\mathrm{C}_{2} \mathrm{~S}$ NPs could promote autophagy. Phosphorylation of the phagocyte-associated AMPK and ULK1 pathways and inhibition of mTOR phosphorylation promoted autophagy. This research additionally verified the expression level of $\beta$-catenin in the Wnt pathway and found that $\mathrm{C}_{2} \mathrm{~S}$ NPs could promote the expression of $\beta$-catenin. We then detected the expression level of relevant proteins in this pathway using an autophagy agonist rapamycin and the autophagy inhibitors 3-MA. We found that the autophagy activator rapamycin and $\mathrm{C}_{2} \mathrm{~S}$ NPs inhibited the phosphorylation of mTOR, upregulated the phosphorylation level of ULK1, and upregulated the expression of $\beta$-catenin using inhibitors, in contrast to the use of 3-MA. However, as observed for osteogenesis,

\footnotetext{
(See figure on next page.)

Fig. $5 C_{2}$ S NPs promote osteogenesis through an autophagy effect in vitro. a The total protein levels of mTOR, p-mTOR, ULK1, p-ULK1, Beclin, P62, and LC3 in BMSCs treated with $C_{2} S$ NPs $(0,10,50,100 \mu \mathrm{g} / \mathrm{mL})$ at different time points ( 7 and 14 days) were detected by western blot analysis, and densitometry data were normalized to GAPDH. The relative optical density was analyzed using ImageJ software (below). b BMSCs were treated with 3-MA, rapamycin, $C_{2} S$ NPs $(50 \mu \mathrm{g} / \mathrm{mL}), C_{2} S$ NPs $+3-M A$, and $C_{2} S$ NPs + rapamycin for 6 h. FITC-labeled LC3 was observed under a fluorescence microscope. The fluorescence intensity ratio was analyzed using ImageJ software (below). ALP activity (c) and the formation of mineralized nodules (d) were detected by BCIP/NBT and Alizarin red S staining, accompanied by 3-MA, rapamycin, $\mathrm{C}_{2} \mathrm{~S} \mathrm{NPs}(50 \mu \mathrm{mg} / \mathrm{mL}), \mathrm{C}_{2} \mathrm{~S} \mathrm{NPs}+3-\mathrm{MA}$, and $C_{2}$ S NPs + rapamycin at different time points (7, 14 days). f Total protein levels of mTOR, p-mTOR, ULK1, p-ULK1, Beclin, P62, LC3 $\beta$-catenin, RUNX2, $B M P 2, O P N$, and Axin1 in BMSCs were detected by western blot analysis. Inhabitor $+C_{2} S$ group compared with $C_{2} S$ group. $f$ Densitometry data were normalized to GAPDH. The relative optical density was analyzed using ImageJ software. Values are expressed as the mean $\pm S E M . n=3 .{ }^{*} p<0.05$, ${ }^{* *} \mathrm{p}<0.01,{ }^{* * *} \mathrm{p}<0.001$. compared with the control group
} 


\section{a}

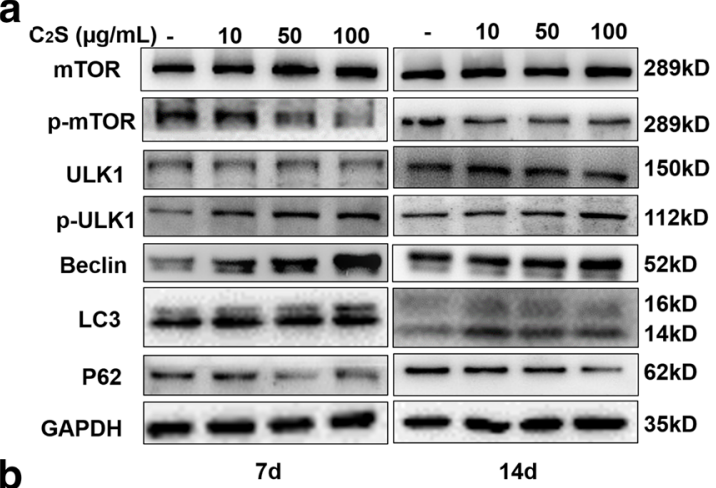

$\begin{array}{llllll}\text { inhibitor } & - & - & + & - & -\end{array}$

${ }_{\text {C2S }}(\mu \mathrm{g} / \mathrm{mL})-$
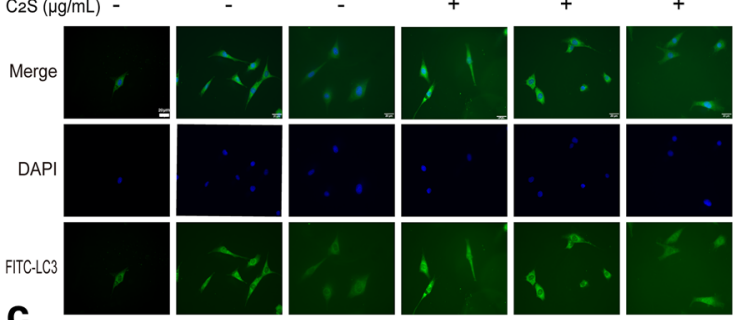

inhibitor
rapa

rapa
$\mathrm{C}_{2} \mathrm{~S}(\mu \mathrm{g} / \mathrm{mL})$
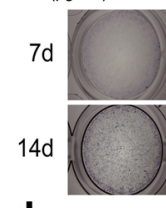

d

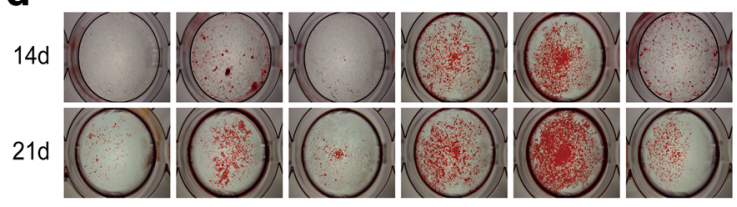

e

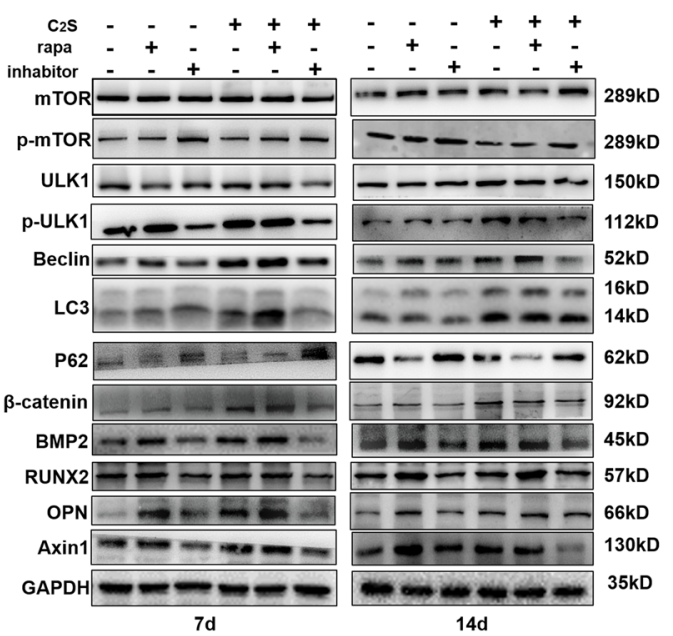

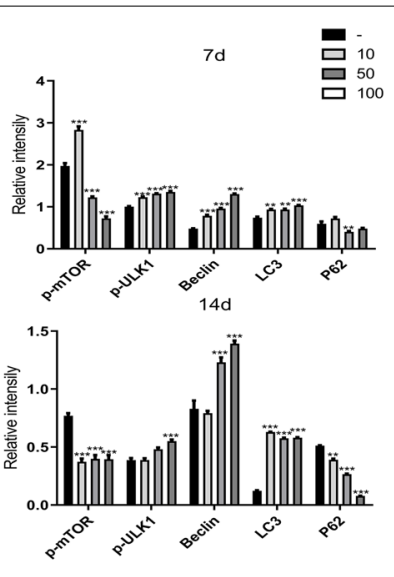

$6 \mathrm{~h}$
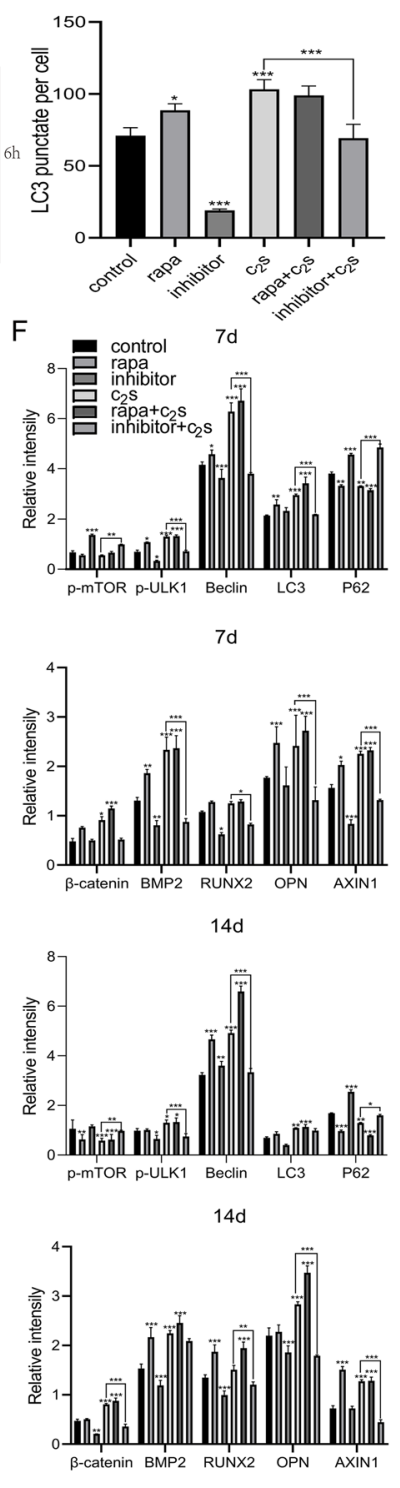
(2)

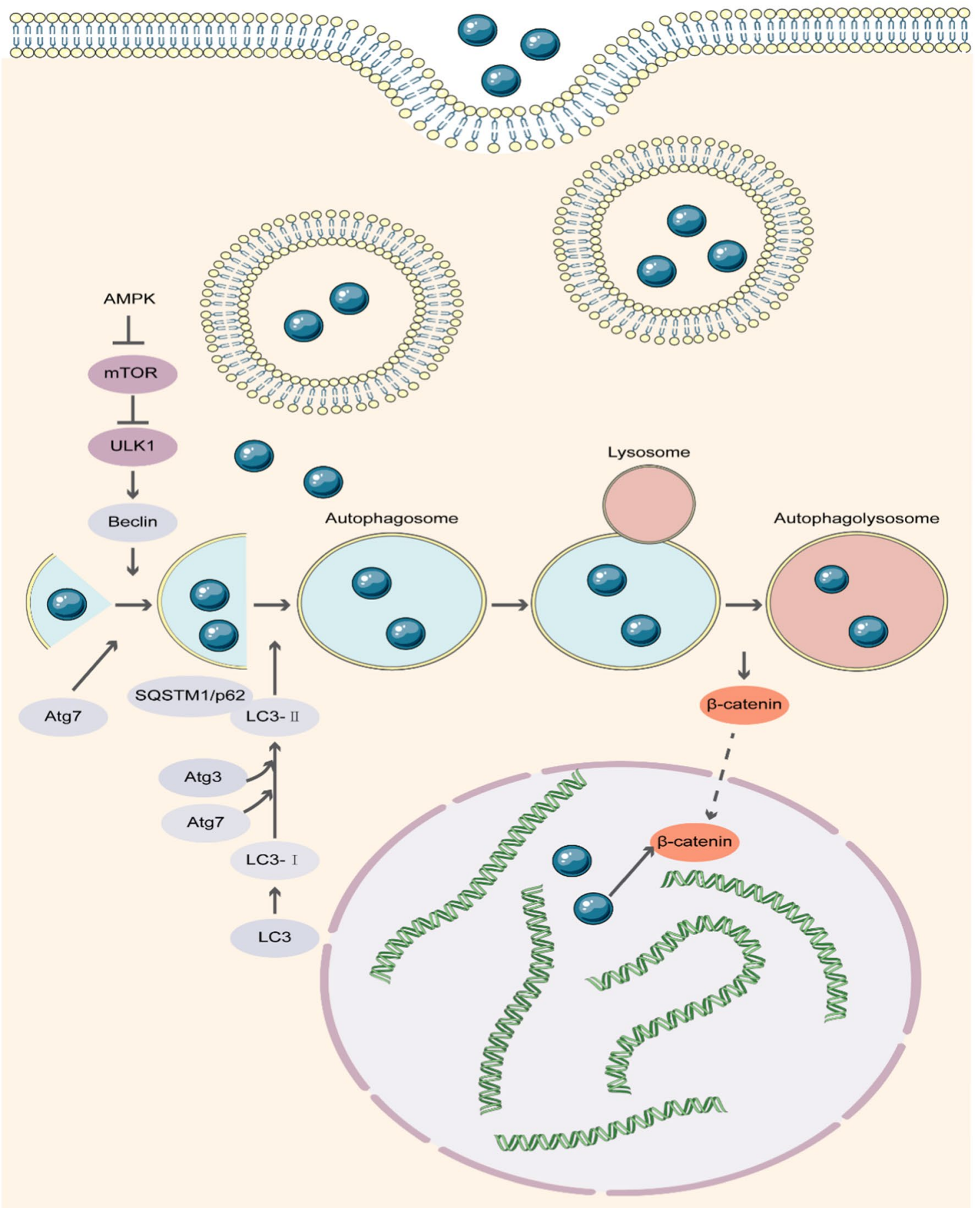

Fig. 6 Signaling pathway by which $C_{2}$ S NPs promote osteogenesis through an autophagy effect. $C_{2} S$ NPs can enter the cell and be trafficked to autophagosomes to activate autophagy and further promote the osteogenic differentiation of MSCs in vitro and in vivo. $C_{2} S$ NPs can activate the mTOR/ULK1 signaling pathway to induce autophagy and activate the Wnt/ $\beta$-catenin pathway to promote osteogenesis. $C_{2} S$ NPs can promote osteogenesis by activating autophagocytosis via the mTOR/ULK1 pathway 


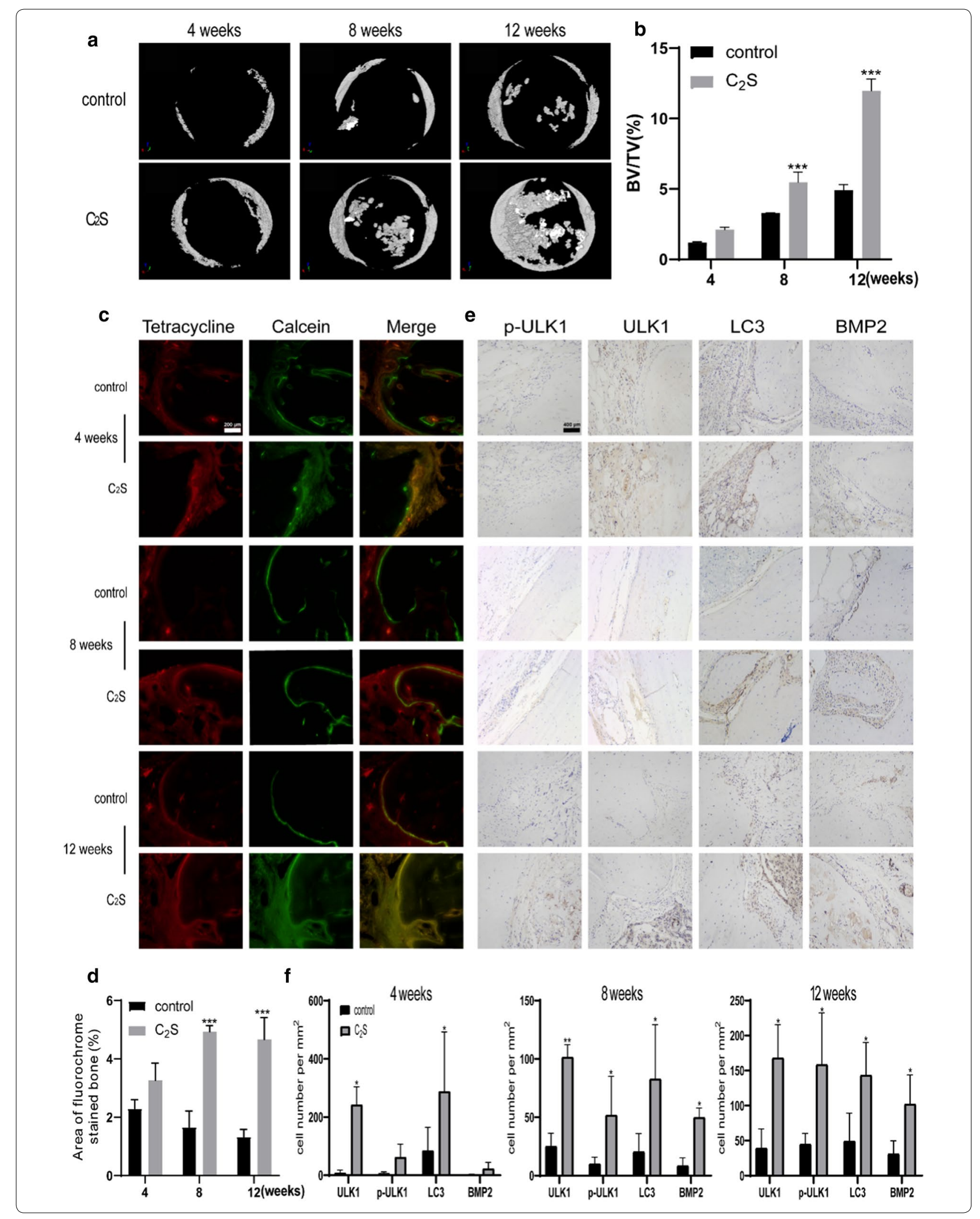


(See figure on previous page.)

Fig. $7 \mathrm{C}_{2}$ S NPs promote osteogenesis through an autophagy effect in vivo. a Micro-computed tomography (micro CT) reconstruction images revealed new bone formation in the defects implanted with $C_{2} S$ NPs at 4,8 , and 12 weeks. $\mathbf{b}$ The relative optical density of new bone formation in the defects was analyzed using ImageJ software. $\mathbf{c}$ Histological images of newly formed bone with $C_{2}$ S NPs at 4, 8, and 12 weeks after surgery. $\mathbf{d}$ The area between the centers of the red band (tetracycline) and the green band (calcein) in the defects was analyzed using ImageJ software. $\mathbf{e}$ Immunohistochemical analysis of the protein expression of BMP2, LC3, ULK1, and $\mathrm{p}-\mathrm{ULK} 1$ in rat calvarial defects after implantation of $\mathrm{C}_{2} S \mathrm{SPS}$ at 4 , 8 , and 12 weeks. $\mathbf{f}$ The relative optical area of new bone formation in the defects was analyzed using ImageJ software. Values are expressed as the mean \pm S.D. $n=3 .{ }^{*} p<0.05,{ }^{* *} p<0.01,{ }^{* *} p<0.001$ compared with the control group

the simultaneous use of inhibitors and $\mathrm{C}_{2} \mathrm{~S}$ NPs could improve the effect of the inhibitor on the expression level of $\beta$-catenin. This phenomenon might be related to our observation that $\mathrm{C}_{2} \mathrm{~S}$ NPs could be taken into the nucleus by cells, followed by direct activation of the transcription factor $\beta$-catenin and mediation of BMSC osteogenic differentiation [39]. Simultaneously, we also found that the expression of ULK1 was upregulated in vivo. The above results indicate that $\mathrm{C}_{2} \mathrm{~S}$ NPs can further activate the Wnt/ $\beta$-catenin pathway by activating the mTOR/ULK1 pathway and autophagy to promote osteogenesis and mineralization.

Our experiments showed that $\mathrm{C}_{2} \mathrm{~S}$ NPs have good biocompatibility and biological activity and can be taken up by cells and promote proliferation, BMSC osteogenic mineralization, and differentiation. In vivo experiments also demonstrated that $\mathrm{C}_{2} \mathrm{~S}$ NPs can promote new bone formation in the bone defect area. $\mathrm{C}_{2} \mathrm{~S}$ NPs can provide raw materials for osteogenic mineralization of BMSCs without activating ALP to promote osteogenesis. The $\mathrm{C}_{2} \mathrm{~S}$ NPs can enter the cell and be trafficked to autophagosomes to activate autophagy and further promote osteogenic differentiation of the MSCs. In vitro and in vivo experiments demonstrated that $\mathrm{C}_{2} \mathrm{~S}$ NPs can activate the mTOR/ULK1 signaling pathway to induce autophagy and activate the $\mathrm{Wnt} / \beta$-catenin pathway to promote osteogenesis. Therefore, $\mathrm{C}_{2} \mathrm{~S}$ NPs can promote osteogenesis by activating autophagocytosis via the mTOR/ULK1 pathway.

\section{Conclusion}

$\mathrm{C}_{2} \mathrm{~S}$ NPs are a kind of bioceramic material with good biocompatibility that can promote osteogenic differentiation and biomineralization by activating autophagy. The mechanism underlying this biological effect consists of $\mathrm{C}_{2} \mathrm{~S}$ NPs activation of the mTOR/ULK1 signaling pathway, induction of autophagy, activation of the Wnt/ $\beta$-catenin pathway, and promotion of osteogenic differentiation and biomineralization.

\section{Supplementary information}

Supplementary information accompanies this paper at https://doi. org/10.1186/s12951-020-00663-w.
Additional file 1: Figure S1. Biocompatibility evaluation of BMSCS exposed to $C_{2} S$ NPs $(0,10,50,100 \mu \mathrm{g} / \mathrm{mL})$. a Uptake of $C_{2} S$ NPs by BMSCs was observed via TEM at 1, 3, and 7 days. $C_{2} S$ NPs shows in the boxes, autophagosomes shows in the arrow. $b$ The levels of $\mathrm{LDH}$ release detected from BMSCs post-treatment with $C_{2} S$ NPs at 7 days. c Cells were stained with Annexin V-FITC and PI and analyzed by flow cytometry. Quantification of the cell early and total apoptosis ratio is shown below on the right. Values are expressed as the mean \pm SEM. $n=3 .{ }^{*} p<0.05,{ }^{* *} p<0.01$, ${ }^{* * *} p<0.001$ compared with the control group.

Additional file 2: Figure S2. a Surgical procedures in vitro. b Body weight change after treatment with $C_{2} S$ NPs for 4,8 , and 12 weeks. c Bone tissue stained with hematoxylin-eosin are treatment with $C_{2} S N P s$ for 4,8 , and 12 weeks. $d$ Van Gieson's picrofuchsin and Stevenel's blue staining of newly formed bone in C2S NPs group at 4, 8, 12 weeks after operation.

\section{Acknowledgements}

This work was funded and supported by the China National Natural Science Foundation (81870786), and (81600904).

\section{Authors' contributions}

WR, CL performed in vivo experiments. WR performed in vitro experiments. $\mathrm{CL}$ provided technical assistance for cell culture method and cytological experiment. The draft manuscript was written by WR. SL contributed to the experiment design. All authors read and approved the final manuscript.

\section{Competing interests}

The authors declare that they have no competing interests.

\section{Author details}

${ }^{1}$ Nanfang Hospital, Southern Medical University, Guangzhou 510515, China. ${ }^{2}$ Guangdong Provincial Key Laboratory of Construction and Detection in Tissue Engineering, Guangzhou 510515, China. ${ }^{3}$ Key Laboratory of Oral Medicine, Guangzhou Institute of Oral Disease, Stomatology Hospital of Guangzhou Medical University, Guangzhou 510140, China.

Received: 27 February 2020 Accepted: 20 July 2020

Published online: 31 August 2020

\section{References}

1. Dong S, Sun J, Li Y, Li J, Cui W, Li B. Electrospun nanofibrous scaffolds of poly (L-lactic acid)-dicalcium silicate composite via ultrasonic-aging technique for bone regeneration. Mater Sci Eng C Mater Biol Appl. 2014;35:426-33.

2. Velasquez P, Luklinska ZB, Meseguer-OImo L, de Val JEMS, Delgado-Ruiz RA, Calvo-Guirado JL, Ramirez-Fernandez MP, de Aza PN. TCP ceramic doped with dicalcium silicate for bone regeneration applications prepared by powder metallurgy method: in vitro and in vivo studies. J Biomed Mater Res Part A. 2013;101(7):1943-54.

3. Chen CC, Ho CC, David Chen CH, Wang WC, Ding SJ. In vitro bioactivity and biocompatibility of dicalcium silicate cements for endodontic use. J Endod. 2009;35(11):1554-7.

4. de Aza PN, Zuleta F, Velasquez P, Vicente-Salar N, Reig JA. alpha '(H) -Dicalcium silicate bone cement doped with tricalcium phosphate: characterization, bioactivity and biocompatibility. J Mater Sci-Mater M. 2014;25(2):445-52. 
5. Wu BC, Huang SC, Ding SJ. Comparative osteogenesis of radiopaque dicalcium silicate cement and white-colored mineral trioxide aggregate in a rabbit femur model. Materials. 2013;6(12):5675-89.

6. Chiang TY, Ding SJ. Comparative physicochemical and biocompatible properties of radiopaque dicalcium silicate cement and mineral trioxide aggregate. J Endodont. 2010;36(10):1683-7.

7. Lai S, Chen L, Cao W, Cui S, Li X, Zhong W, Ma M, Zhang Q. Dicalcium silicate induced proinflammatory responses through TLR2-mediated NF-kappaB and JNK pathways in the murine RAW 264.7 macrophage cell line. Mediators Inflamm. 2018. https://doi.org/10.1155/2018/8167932.

8. Chen, L. J.; Zhang, Y. L.; Liu, J.; Wei, L. M.; Song, B.; Shao, L. Q., Exposure of the murine RAW 264.7 macrophage cell line to dicalcium silicate coating: assessment of cytotoxicity and pro-inflammatory effects. J Mater SciMater M 2016, 27 (3)59.

9. Radwan MM, Abd El-Hamid HK, Mohamed AF. Influence of saline solution on hydration behavior of beta-dicalcium silicate in comparison with biphasic calcium phosphate/hydroxyapatite bio-ceramics. Mat Sci Eng C-Mater. 2015:57:355-62.

10. Qi M, Zhang L, Ma Y, Shuai Y, Li L, Luo K, Liu W, Jin Y. Autophagy maintains the function of bone marrow mesenchymal stem cells to prevent estrogen deficiency-induced osteoporosis. Theranostics. 2017;7(18):4498-516.

11. Lin NY, Chen CW, Kagwiria R, Liang RF, Beyer C, Distler A, Luther J, Engelke K, Schett G, Distler JHW. Inactivation of autophagy ameliorates glucocorticoid-induced and ovariectomy-induced bone loss. Ann Rheum Dis. 2016;75(6):1203-10.

12. Song S, Yu J, Xiao Q, Ye X, Zhong Y, Zhu W. A stepwise loading method to magnetically responsive Pt-Fe3O 4/MCNT catalysts for selective hydrogenation of 3-methylcrotonaldehyde. Nanoscale Res Lett. 2014;9(1):2498.

13. Ma, Y.; Qi, M.; An, Y.; Zhang, L.; Yang, R.; Doro, D. H.; Liu, W.; Jin, Y., Autophagy controls mesenchymal stem cell properties and senescence during bone aging. Aging Cell 2018, 17 (1)

14. Nuschke A, Rodrigues M, Stolz DB, Chu CT, Griffith L, Wells A. Human mesenchymal stem cells/multipotent stromal cells consume accumulated autophagosomes early in differentiation. Stem Cell Res Ther. 2014;5(6):140.

15. Li Y, Su J, Sun W, Cai L, Deng Z. AMP-activated protein kinase stimulates osteoblast differentiation and mineralization through autophagy induction. Int J Mol Med. 2018;41(5):2535-44.

16. Ha SW, Weitzmann MN, Beck GR. Bioactive silica nanoparticles promote osteoblast differentiation through stimulation of autophagy and direct association with LC3 and p62. ACS Nano. 2014;8(6):5898-910.

17. Chen HQ, Liu XB, Chen $\mathrm{H}$, Cao J, Zhang L, Hu XY, Wang JA. Role of SIRT1 and AMPK in mesenchymal stem cells differentiation. Ageing Res Rev. 2014;13:55-64

18. Wu JH, Ren BW, Shi FL, Hua P, Lin H. BMP and mTOR signaling in heterotopic ossification: does their crosstalk provide therapeutic opportunities? J Cell Biochem. 2019;120(8):12108-22.

19. Zhou T, Yan YR, Zhao CC, Xu Y, Wang Q, Xu N. Resveratrol improves osteogenic differentiation of senescent bone mesenchymal stem cells through inhibiting endogenous reactive oxygen species production via AMPK activation. Redox Rep. 2019;24(1):62-9.

20. Li Z, Liu X, Zhu Y, Du Y, Liu X, Lv L, Zhang X, Liu Y, Zhang P, Zhou Y. Mitochondrial phosphoenolpyruvate carboxykinase regulates osteogenic differentiation by modulating AMPKULLK1-dependent autophagy. Stem Cells. 2019;37(12):1542-55.

21. Carbonare, L. D.; Mottes, M.; Cheri, S.; Deiana, M.; Zamboni, F.; Gabbiani, D.; Schena, F.; Salvagno, G. L.; Lippi, G.; Valenti, M. T., Increased Gene Expression of RUNX2 and SOX9 in Mesenchymal Circulating Progenitors Is Associated with Autophagy during Physical Activity. Oxid Med Cell Longev 2019

22. Zhou Z, Shi G, Zheng X, Jiang S, Jiang L. Autophagy activation facilitates mechanical stimulation-promoted osteoblast differentiation and ameliorates hindlimb unloading-induced bone loss. Biochem Biophys Res Commun. 2018;498(3):667-73.

23. Liu X, He J, Zhang SM, Wang XM, Liu HY, Cui FZ. Adipose stem cells controlled by surface chemistry. J Tissue Eng Regen M. 2013;7(2):112-7.

24. Arumugam V, Venkatesan M, Ramachandran S, Sundaresan U. Bioactive peptides from marine ascidians and future drug development-A review. Int J Pept Res Ther. 2018;24(1):13-8.

25. Fu HL, Rahaman MN, Brown RF, Day DE. Evaluation of bone regeneration in implants composed of hollow HA microspheres loaded with transforming growth factor beta 1 in a rat calvarial defect model. Acta Biomater. 2013;9(3):5718-27.

26. Vieira S, Vial S, Reis RL, Oliveira JM. Nanoparticles for bone tissue engineering. Biotechnol Progr. 2017;33(3):590-611.

27. Meseguer-Olmo L, Aznar-Cervantes S, Mazon P, De Aza PN. "In vitro" behaviour of adult mesenchymal stem cells of human bone marrow origin seeded on a novel bioactive ceramics in the Ca2SiO4-Ca-3(PO4)(2) system. J Mater Sci-Mater M. 2012;23(12):3003-14.

28. Correa D, Almirall A, Carrodeguas RG, dos Santos LA, De Aza AH, Parra J, Morejon L, Delgado JA. alpha-Tricalcium phosphate cements modified with beta-dicalcium silicate and tricalcium aluminate: physicochemical characterization, in vitro bioactivity and cytotoxicity. J Biomed Mater Res B. 2015;103(1):72-83.

29. McAuliffe ME, Perry MJ. Are nanoparticles potential male reproductive toxicants? a literature review. Nanotoxicology. 2007;1(3):204-10.

30. Manj, R. Z. A.; Chen, X. Q.; Rehman, W. U.; Zhu, G. J.; Luo, W.; Yang, J. P., Big Potential From Silicon-Based Porous Nanomaterials: In Field of Energy Storage and Sensors. Front Chem 2018, 6, 539.

31. Patel S, Kim J, Herrera M, Mukherjee A, Kabanov AV, Sahay G. Brief update on endocytosis of nanomedicines. Adv Drug Deliver Rev. 2019;144:90-111.

32. Hench LL, Paschall HA. Direct chemical bond of bioactive glass-ceramic materials to bone and muscle. J Biomed Mater Res. 1973;7(3):25-42.

33. Li HW, Sun JY. Effects of dicalcium silicate coating ionic dissolution products on human mesenchymal stem-cell proliferation and osteogenic differentiation. J Int Med Res. 2011;39(1):112-28.

34. Dou XJ, Wei XW, Liu G, Wang S, LV YX, Li JL, Ma ZJ, Zheng GS, Wang YK, Hu $\mathrm{MH}, \mathrm{Yu}$ WT, Zhao DW. Effect of porous tantalum on promoting the osteogenic differentiation of bone marrow mesenchymal stem cells in vitro through the MAPK/ERK signal pathway. J Orthop Transl. 2019;19:81-93.

35. Xiao L, Xiao Y. The autophagy in osteoimmonology: self-eating, maintenance, and beyond. Front Endocrinol. 2019;10:490.

36. Singh, R. K.; Haka, A. S.; Chin, H. F.; Grosheva, l.; Maxfield, F. R., TLR4 Signaling Regulates Lysosome Exocytosis to a Novel Extracellular Compartment. Faseb Journal 2013, 27,.

37. Stern ST, Adiseshaiah PP, Crist RM. Autophagy and lysosomal dysfunction as emerging mechanisms of nanomaterial toxicity. Part Fibre Toxicol. 2012;9:20.

38. Randhawa R, Sehgal M, Singh TR, Duseja A, Changotra H. Unc-51 like kinase 1 (ULK1) in silico analysis for biomarker identification: a vital component of autophagy. Gene. 2015;562(1):40-9.

39. Zhao XE, Yang ZS, Gao Z, Ge JB, Wei Q, Ma BH. 6-Bromoindirubin-3'-oxime promotes osteogenic differentiation of canine BMSCs through inhibition of GSK3 beta activity and activation of the Wnt/beta-catenin signaling pathway. An Acad Bras Cienc. 2019. https://doi.org/10.1590/0001-37652 01920180459.

\section{Publisher's Note}

Springer Nature remains neutral with regard to jurisdictional claims in published maps and institutional affiliations. 